\title{
Connexins in cancer: bridging the gap to the clinic
}

\author{
Trond Aasen (1) ${ }^{1}$ Edward Leithe ${ }^{2} \cdot$ Sheila V. Graham ${ }^{3} \cdot$ Petra Kameritsch $^{4} \cdot$ María D. Mayán $^{5} \cdot$ Marc Mesnil $^{6} \cdot$ \\ Kristin Pogoda ${ }^{4} \cdot$ Arantxa Tabernero $\mathbb{1}^{7}$
}

Received: 22 November 2018 / Revised: 26 January 2019 / Accepted: 26 January 2019 / Published online: 27 February 2019

(c) The Author(s) 2019. This article is published with open access

\begin{abstract}
Gap junctions comprise arrays of intercellular channels formed by connexin proteins and provide for the direct communication between adjacent cells. This type of intercellular communication permits the coordination of cellular activities and plays key roles in the control of cell growth and differentiation and in the maintenance of tissue homoeostasis. After more than 50 years, deciphering the links among connexins, gap junctions and cancer, researchers are now beginning to translate this knowledge to the clinic. The emergence of new strategies for connexin targeting, combined with an improved understanding of the molecular bases underlying the dysregulation of connexins during cancer development, offers novel opportunities for clinical applications. However, different connexin isoforms have diverse channel-dependent and -independent functions that are tissue and stage specific. This can elicit both pro- and anti-tumorigenic effects that engender significant challenges in the path towards personalised medicine. Here, we review the current understanding of the role of connexins and gap junctions in cancer, with particular focus on the recent progress made in determining their prognostic and therapeutic potential.
\end{abstract}

\section{Introduction}

Connexins are integral membrane proteins that form channels between adjacent cells and thereby permit the bidirectional cytosolic exchange of ions, metabolites and secondary messengers $(<\sim 1200 \mathrm{Da})$ (Fig. 1a) [1]. These channels assemble into distinct plasma membrane domains termed gap junctions (Fig. 1b) [1]. Gap junction intercellular communication (GJIC) plays essential roles in

These authors contributed equally: Trond Aasen, Edward Leithe

Trond Aasen

trond.aasen@vhir.org

$\triangle$ Arantxa Tabernero

ataber@usal.es

1 Translational Molecular Pathology, Vall d'Hebron Institute of Research (VHIR), Autonomous University of Barcelona, CIBERONC, Barcelona, Spain

2 Department of Molecular Oncology, Institute for Cancer Research, Oslo University Hospital and K.G. Jebsen Colorectal Cancer Research Centre, Oslo University Hospital, Oslo, Norway

3 MRC-University of Glasgow Centre for Virus Research, Institute of Infection, Immunity and Inflammation, College of Medical, tissue homoeostasis and regulation of cell growth and differentiation [2]. In addition, connexins form functional channels at the non-junctional areas of the plasma membrane (Fig. 1) [3]. These so-called hemichannels provide a communication pathway between the intracellular and extracellular milieus that is important in autocrine and paracrine signalling [3]. Connexins also possess significant channel-independent roles, including the one as signalling hubs, which may occur at the plasma membrane, in the cytoplasm or even in the nucleus [2].

The human connexin protein family contains $21 \mathrm{mem}-$ bers, of which the most widely studied is connexin 43 (Cx43) [2]. A large body of experimental evidence suggests

Veterinary and Life Sciences, University of Glasgow,

Glasgow, UK

4 Walter Brendel Centre of Experimental Medicine, LudwigMaximilians-Universität München and Munich University Hospital, München, Germany

5 CellCOM Research Group, Instituto de Investigación Biomédica de A Coruña (INIBIC), Servizo Galego de Saúde (SERGAS), University of A Coruña, A Coruña, Spain

6 STIM Laboratory, Faculté des Sciences Fondamentales et Appliquées, Université de Poitiers, Poitiers, France

7 Departamento de Bioquímica y Biología Molecular, Instituto de Neurociencias de Castilla y León (INCYL), Universidad de Salamanca, Salamanca, Spain 
A

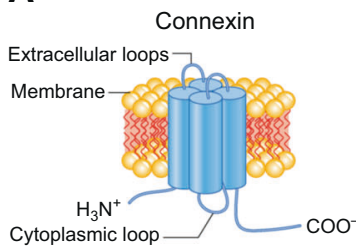

Connexon

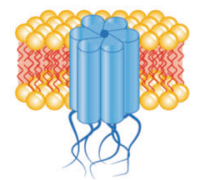

Gap junction intercellular channel

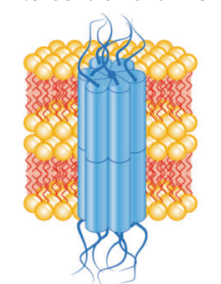

B

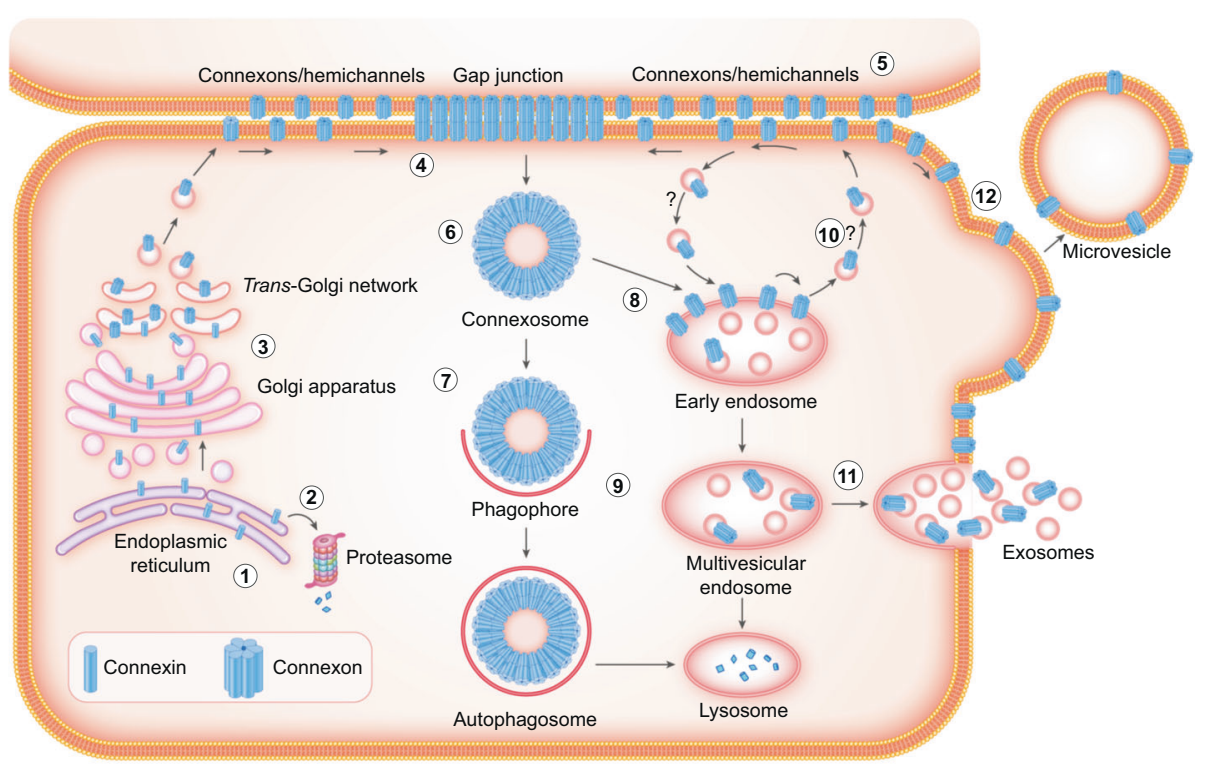

Fig. 1 Connexins, connexons and gap junctions. a Connexins are tetraspanning integral membrane proteins with cytosolic $\mathrm{C}$ and $\mathrm{N}$ termini. Six connexins oligomerize to form a connexon. At the plasma membrane, the connexon can dock head-to-head with a connexon in an adjacent cell to form a gap junction intercellular channel. b Biosynthesis, intracellular trafficking and degradation of connexins. (1) Connexins are cotranslationally inserted into the endoplasmic reticulum. (2) A subpool of newly synthesised connexins undergo endoplasmic reticulum-associated degradation. (3) During their trafficking to the plasma membrane, connexins oligomerise into connexons. (4) After their arrival at the plasma membrane, the connexons can dock with connexons from adjacent cells to form gap junction channels. (5) Connexons may also form functional channels at the non-junctional areas of the plasma membrane (also known as hemichannels). (6) Gap

that connexins are causally involved in cancer pathogenesis, possessing both pro- and anti-tumorigenic functions (see the below section and recent reviews [2, 4]). Significant advances have been made towards understanding how connexins can act as either tumour suppressors or tumour promoters depending on the isoform, cancer stage and tissue. In addition to the emerging prognostic value of connexins in cancer, several studies indicate that connexin targeting might have considerable therapeutic implications $[5,6]$. This review provides an overview of our current understanding of the role of connexins in cancer, with emphasis on their prognostic and therapeutic potential.

\section{Complex roles of connexins in cancer}

\section{Connexins as tumour suppressors}

The idea that GJIC regulates tumour growth was proposed by Loewenstein and Kanno more than 50 years ago in a junction endocytosis results in the formation of a connexosome (also known as annular gap junction). (7) The connexosome may be degraded by autophagy. (8) Alternatively, the connexosome may change its morphology to that of a connexin-enriched multivesicular endosome in a process that is associated with the fusion between the connexosome and early endosomes. (9) Connexins are sorted from early endosomes to lysosomes via late endosomes. (10) Under certain conditions, endocytosed connexons may undergo recycling to the plasma membrane. Hemichannels also undergo endocytosis and recycling, but their endocytic and recycling pathways are poorly characterised (question marks). (11) Multivesicular endosomes can fuse with the plasma membrane to secrete exosomes containing connexons. (12) Microvesicles containing connexons can be formed by the outward budding of the plasma membrane

seminal ex vivo study, in which they demonstrated the loss of electrical coupling occurring in rat liver tumours [7]. Since then, several connexin knockout mouse models have supported the notion that connexins have tumoursuppressive functions (reviewed in ref. [2]), notably Cx32 (multiple organs), Cx43 (breast and lung) and Cx26 (breast). Cancer cells often display a loss of GJIC due to the dysregulation of connexin expression at multiple levels (Fig. 2). At the transcriptional level, the reduced connexin expression in tumours involves transcriptional and epigenetic mechanisms such as promoter methylation [8-11]. At the post-transcriptional level, the suppression of connexin expression can be due to connexin-targeting microRNAs $[12,13]$. At the protein-synthesis level, internal translation of N-terminally truncated forms of $\mathrm{Cx} 43$ [14-16] has recently been described to regulate connexin membrane targeting [14], and Smad3/ERK-dependent repression of this process was reported to reduce $\mathrm{Cx} 43$ gap junctions during epithelial-to-mesenchymal transition [17]. At the post-translational level, many growth factors, oncogenes 
and tumour-promoting chemicals are potent inducers of Cx43 phosphorylation, which is often associated with the inhibition of GJIC [18] and increased Cx43 ubiquitination, endocytosis and degradation [19].

In accordance with the notion that connexins might act as tumour suppressors, the ectopic expression of connexins in cancer cells often partly restores growth control (e.g. refs. [20-25]) and differentiation potential (e.g. refs. [26-28], reviewed in ref. [2]). Conversely, the experimental depletion of connexins may result in more aggressive cancer cell growth [29]. In addition to their role in modulating cell proliferation [30], connexins can either promote or prevent cell death by apoptosis [31]. Such effects may be due to the gap junction-mediated intercellular passage of survival or death signals such as $\mathrm{Ca}^{2+}, \mathrm{IP}_{3}$ and cAMP [2, 32-34]. Moreover, hemichannels may exchange proapoptotic and survival factors between extracellular and intracellular environments [35].

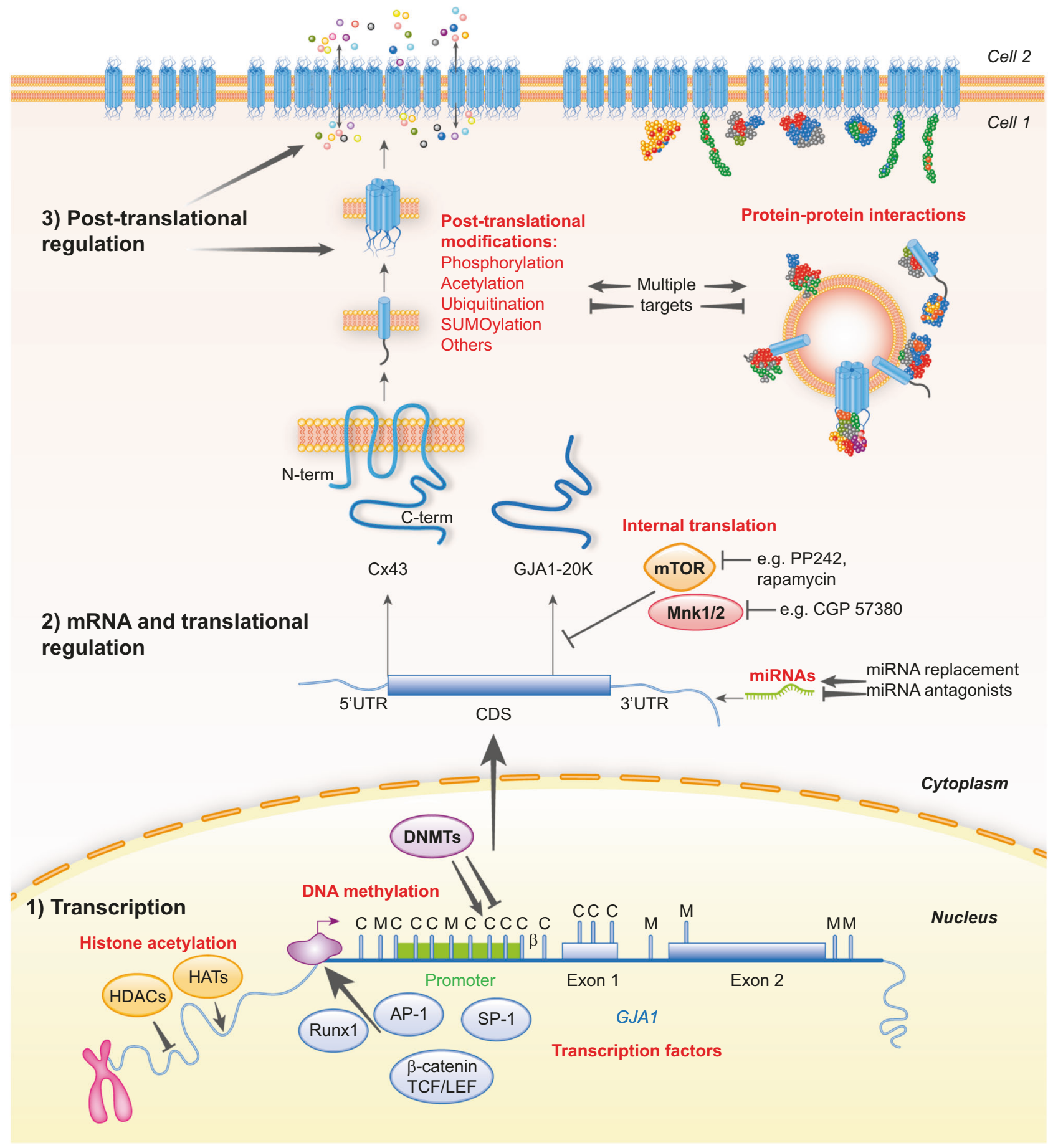


Fig. 2 Dysregulation of connexins in cancer: therapeutic opportunities. Multiple stages of connexin life cycle are subject to dysregulation during cancer progression, as exemplified by GJAl (Cx43). (1) Transcription: connexin expression is often reduced (but sometimes increased) in human tumours at the mRNA expression level, of which multiple pathways are therapeutic targets (text highlighted in red for key targets), including transcription factor activity and epigenetic silencing by histone acetylation and promoter methylation (promoter region in green, with $\mathrm{C}$ and $\mathrm{M}$ illustrating the non-methylated and methylated sites, respectively; blue, some important transcription factors regulating $\mathrm{Cx} 43$ expression). Histone acetylation can be modified by targeting histone acetyltransferase enzymes (HATs) or histone deacetylases (HDACs), typically promoting and repressing transcription, respectively. Transcriptional silencing due to promoter hypermethylation by DNA methyltransferase enzymes (DNMTs) may also be amenable to therapeutic intervention leading to the restoration of GJIC. (2) mRNA regulation: mRNA stability and translation is subject to regulation by multiple cancer-associated microRNAs. Moreover, alternative translation initiation, resulting in the synthesis of truncated forms of $\mathrm{Cx} 43$, might regulate $\mathrm{Cx} 43$ and have important implications for its dysregulation in cancer. This process is regulated by key cancer signalling pathways such as mTOR and Mnk1/2 and is altered during pathological conditions such as hypoxia. Truncated forms of $\mathrm{Cx} 43$, notably the $20-\mathrm{kDa}$ form named GJA1-20k, may be important for the efficient targeting of $\mathrm{Cx} 43$ to the membrane. Indeed, Smad3/ERK-dependent repression of GJA1-20k was recently shown to reduce $\mathrm{Cx} 43$ gap junctions during epithelial-to-mesenchymal transition (EMT). (3) Post-translational regulation: connexins frequently display an aberrant localisation in cancer cells. Phosphorylation and other multiple post-translational events, occurring mainly at their $\mathrm{C}$ terminus, regulate connexin trafficking and stability at the plasma membrane. $\mathrm{Cx} 43$ is regulated by several kinases that are frequently overactivated or overexpressed during cancer development and susceptible to pharmacological inhibition, such as mitogen-activated protein kinase (MAPK), protein kinase $\mathrm{C}$ (PKC), protein kinase $\mathrm{A}$ (PKA), cdc2/cyclin B and $\mathrm{v}$-src/c-src. $\mathrm{Cx} 43$ is also regulated by acetylation, ubiquitination and SUMOylation

There is increasing evidence that connexins can suppress the growth of cancer cells through channel-independent mechanisms [22, 30, 36-39] (Fig. 3). For example, the ectopic expression of the intracellular C terminus (CT) of $\mathrm{Cx} 43$ can in some cases inhibit cell proliferation to a similar extent as full-length protein [24]. Connexins may also modulate the activity of some of their partners by affecting their cellular location, as proposed by Skp2 for Cx50 [40], $\beta$ catenin for $\mathrm{Cx} 43$ [38], discs large homologue 1 (Dlgh1) for Cx32 [41] and Cx43 [42], or by other mechanisms, such as the recruitment of Src together with its endogenous inhibitors CSK and PTEN resulting in a switch from the active to inactive conformation of c-Src [43] (Fig. 3). Because connexins present a low level of homology within their CT sequences, the channel-independent regulation of cell growth is expected to vary considerably among different isoforms.

\section{Connexins as promoters of invasion and metastasis}

When assessing the role of connexins in cancer pathogenesis, we must consider that their ability to act as tumour suppressors can vary considerably among tissue types and cancer stages, as well as among connexin isoforms [2]. Furthermore, there is growing evidence that some connexin isoforms are protumorigenic under certain conditions. For example, connexins can promote the migration and invasion of tumour cells [44, 45]. In addition, connexins can form heterologous gap junctions between tumour cells and endothelial cells to facilitate intravasation and extravasation [46-49]. Connexins can also nurture metastatic growth and may promote resistance to cancer treatments [50-53]. In accordance with this notion, a recent study demonstrated that brain metastatic cancer cells establish gap junctions with astrocytes to promote tumour growth and chemoresistance [50].

\section{Connexins and cancer stem cells}

Emerging experimental evidence indicates that connexins play important roles in cancer stem cell (CSC) biology. Malignant glioma stem cells (GSCs) express very low levels of Cx43, and GSC stemness is reduced by its transfection with $\mathrm{Cx} 43$ or treatment with peptides containing sequences of $\mathrm{Cx} 43$ that interact with c-Src (Cx43 mimetic peptides) $[54,55]$. A recent work has found that the expression levels of $\mathrm{Cx} 43$ and $\mathrm{Cx} 46$ were increased and reduced, respectively, during GSC differentiation and that targeting of Cx46 compromises GSC maintenance [56]. While Cx43 is almost absent in liver CSCs [57], the accumulation of cytoplasmic $\mathrm{Cx} 32$ has been associated with metastasis and enhanced self-renewal of CSCs in human $\mathrm{HuH7}$ hepatoma cells [58]. Some subtypes of breast cancer cells positive for the putative CSC marker CD44 express Cx43 [59, 60]. Moreover, $\mathrm{Cx} 43$ clearly plays a subtype-dependent role in breast cancer [61]. In triple-negative breast cancers, Cx26 was shown to be upregulated in CSC population, in which it forms a complex with NANOG and focal adhesion kinase to drive self-renewal (Fig. 3) [62].

Overall, connexins can be both anti- and pro-tumorigenic, acting via processes that include the regulation of CSCs, and this depends on the connexin isoform and tissue type. Understanding this complexity is the key to the development of new and efficient therapies.

\section{Prognostic value of connexins in cancer}

A number of studies suggest that connexins can be independent tumour markers predicting both better and worse prognoses. Further insights into this seeming contradiction have been provided by recent analytical tools for public databases. The Pathology Atlas within the Human Protein Atlas database (https://www.proteinatlas.org/pathology) includes an open-access database (retrieved from The 


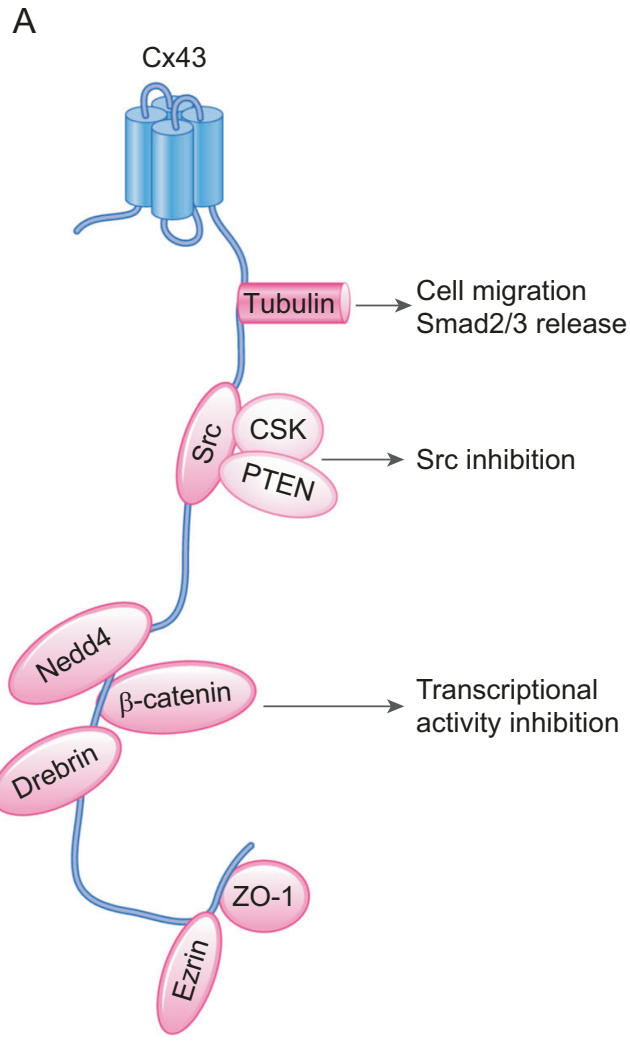

Fig. 3 Interactions between connexins and proteins that affect tumour growth and migration. Examples of proteins that interact with specific regions of connexins and may act as therapy targets. a The interaction between $\mathrm{Cx} 43$ and tubulin is involved in the regulation of cell migration. Similar mechanisms have been proposed for other proteins associated with the cytoskeleton, such as cadherins, catenins, vinculin, ZO-1 and drebrin. In addition, Cx43 may compete with the tubulinSmad2/3 interaction causing Smad2/3 release. Cx43 binds to c-Src and its endogenous inhibitors CSK and PTEN, promoting c-Src inhibition. $\mathrm{Cx} 43$, by interacting with $\beta$-catenin, prevents the transcriptional activity of $\beta$-catenin in the nucleus, where it regulates the expression of genes involved in promoting cell malignancy. A similar sequestration mechanism may occur with drebrin, ezrin or ZO-1. These proteins, and many others such as Nedd4, also have important roles in regulating $\mathrm{Cx} 43$ gap junction plaques, which influence GJIC and therefore may

Cancer Genome Atlas (TCGA)) containing correlation analyses based on mRNA expression levels with respect to the clinical outcome for 17 major cancer types and almost 8000 cancer patients [63]. Those mRNAs encoding connexins identified to have a highly significant prognostic value $(P<0.001)$ in any of these cancer types are summarised in Table 1. Notably, GJAl (encoding Cx43) is featured in the list of 20 genes most significantly associated with an unfavourable prognosis in stomach cancer. Indeed, for most connexins and cancer types, high levels of connexin mRNA expression are associated with a poor prognosis. It is also notable that the mRNA expression of a given connexin-encoding gene can be both favourable and unfavourable, depending on the type of tumour (Table 1). Different connexins can also have differing prognostic
C

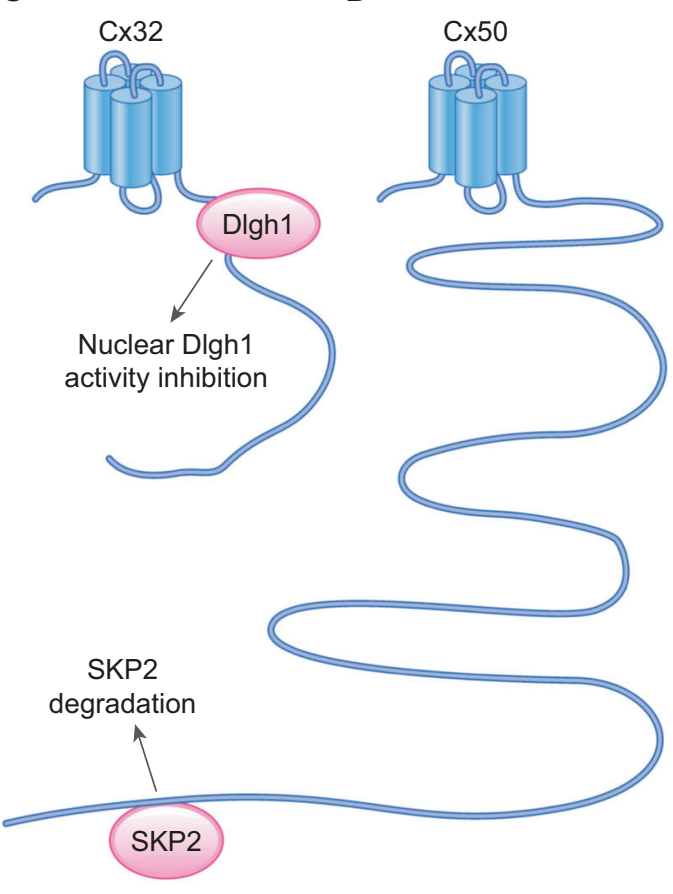

have therapeutic potential. b $\mathrm{Cx} 26$ has been proposed to maintain a cancer stem cell phenotype specifically in triple-negative breast cancer cells through its interaction with NANOG and focal adhesion kinase (FAK). c Cx32 binds to the scaffold protein discs large homologue 1 (Dlgh1) and may control cell proliferation in liver cells through its interaction with and maintenance of Dlgh1 at the plasma membrane. The interaction of Dlgh with $\mathrm{Cx} 43$ has also been associated with cancer progression through a mechanism involving the oncoprotein E6 (see section "Connexins and tumour viruses"). d Cx50 interacts with and promotes auto-ubiquitination and the subsequent degradation of Skp2, a key negative regulator of the cyclin-dependent kinase (CDK) inhibitor p27. a-d To complicate this scenario, the phosphorylation of connexins modifies their binding affinities to various protein partners. For instance, c-Src phosphorylation affects the binding of several Cx43 partners. GJIC, gap junction intercellular communication

prediction results for the same type of tumour (e.g. Cx26 vs Cx32 in renal cancer). The sub-classification of cancers is also relevant. For example, the Kaplan-Meier Plotter tool (http://kmplot.com/analysis) suggests that high levels of Cx43 mRNA are associated with good and poor prognoses in oestrogen receptor-positive and -negative breast cancer subtypes, respectively [64].

Several specific studies have also reported a correlation between connexin mRNA levels and survival or phenotypic features. For instance, high levels of Cx43 mRNA in glioma tumours have been correlated with poor survival [65]. Expression of connexin mRNA in the surrounding tissue may also correlate with a specific tumour phenotype or behaviour. For example, in melanoma, the increased expression of $\mathrm{Cx} 26$ and $\mathrm{Cx} 30$ at the mRNA level in the 
Table 1 Significant associations between connexin mRNA expression and cancer prognosis

\begin{tabular}{|c|c|c|c|c|}
\hline Connexin (gene) & Cancer & Clinical relevance & Survival, ${ }^{\mathrm{a}} \%$ alive & $P$ value (best separation) \\
\hline \multirow[t]{6}{*}{ Cx26 (GJB2) } & Renal & $\mathrm{U}$ & $H=52 \%(n=188), L=73 \%(n=689)$ & $5.98 \mathrm{E}-04$ \\
\hline & KIRC & $\mathrm{U}$ & $H=46 \%(n=130), L=70 \%(n=398)$ & $7.79 \mathrm{E}-05$ \\
\hline & Pancreatic & $\mathrm{U}$ & $H=15 \%(n=86), L=40 \%(n=90)$ & $2.90 \mathrm{E}-04$ \\
\hline & Glioma & $\mathrm{U}$ & $H=0 \%(n=39), L=11 \%(n=114)$ & $5.98 \mathrm{E}-04$ \\
\hline & Lung $^{\mathrm{b}}$ & $\mathrm{U}$ & $H=43 \%(n=795), L=49 \%(n=199)$ & $6.25 \mathrm{E}-04$ \\
\hline & LUAD $^{b}$ & $\mathrm{U}$ & $H=33 \%(n=330), L=53 \%(n=170)$ & $1.45 \mathrm{E}-05$ \\
\hline \multirow[t]{2}{*}{ Cx30.3 (GJB4) } & Pancreatic & $\mathrm{U}$ & $H=15 \%(n=139), L=66 \%(n=37)$ & $3.24 \mathrm{E}-05$ \\
\hline & Cervical & $\mathrm{F}$ & $H=74 \%(n=181), L=52 \%(n=110)$ & $5.48 \mathrm{E}-04$ \\
\hline \multirow[t]{3}{*}{ Cx31 (GJB3) } & Pancreatic & $\mathrm{U}$ & $H=15 \%(n=70), L=37 \%(n=106)$ & $7.56 \mathrm{E}-05$ \\
\hline & Lung $^{\mathrm{b}}$ & $\mathrm{U}$ & $H=44 \%(n=709), L=45 \%(n=285)$ & $4.56 \mathrm{E}-04$ \\
\hline & LUAD $^{\mathrm{b}}$ & $\mathrm{U}$ & $H=18 \%(n=107), L=45 \%(n=393)$ & $3.54 \mathrm{E}-08$ \\
\hline Cx31.1 (GJB5) & Pancreatic & $\mathrm{U}$ & $H=0 \%(n=66), L=42 \%(n=110)$ & $1.54 \mathrm{E}-04$ \\
\hline \multirow[t]{2}{*}{ Cx32 (GJB1) } & Renal $^{\text {b }}$ & $\mathrm{F}$ & $H=77 \%(n=451), L=61 \%(n=426)$ & $2.85 \mathrm{E}-06$ \\
\hline & $\mathrm{KIRC}^{\mathrm{b}}$ & $\mathrm{F}$ & $H=75 \%(n=284), L=50 \%(n=244)$ & $4.88 \mathrm{E}-08$ \\
\hline \multirow[t]{4}{*}{ Cx37 (GJA4) } & Renal $^{\mathrm{b}}$ & $\mathrm{U}$ & $H=67 \%(n=700), L=80 \%(n=177)$ & 7.44E-04 \\
\hline & $\mathrm{KIRC}^{\mathrm{b}}$ & $\mathrm{F}$ & $H=68 \%(n=417), L=48 \%(n=111)$ & 8.57E-04 \\
\hline & $\mathrm{KIRP}^{\mathrm{b}}$ & $\mathrm{U}$ & $H=58 \%(n=77), L=82 \%(n=208)$ & $1.07 \mathrm{E}-05$ \\
\hline & Liver & $\mathrm{F}$ & $H=53 \%(n=225), L=39 \%(n=140)$ & $3.28 \mathrm{E}-04$ \\
\hline \multirow[t]{2}{*}{$\mathrm{Cx} 43(G J A 1)$} & Stomach & $\mathrm{U}$ & $H=14 \%(n=98), L=45 \%(256)$ & 4.99E-05 \\
\hline & $\mathrm{KIRC}^{\mathrm{b}}$ & $\mathrm{F}$ & $H=68 \%(n=409), L=45 \%$ & $2.60 \mathrm{E}-04$ \\
\hline \multirow[t]{2}{*}{$\mathrm{Cx} 45(G J C 1)$} & Renal & $\mathrm{U}$ & $H=63 \%(n=562), L=80 \%(n=316)$ & $3.55 \mathrm{E}-08$ \\
\hline & Urothelial & $\mathrm{U}$ & $H=34 \%(n=286), L=58 \%(n=120)$ & 7.83E-04 \\
\hline
\end{tabular}

a Survival: percentage of patients alive after 3 years for glioma and 5 years for all other cancer types. The table and the $P$ values are based on a bestfit model in which patient numbers $(n)$ are stratified into high $(\mathrm{H})$ and low $(\mathrm{L})$ connexin expression groups

${ }^{b}$ Cancer subtype-specific evidence (i.e. only some subtypes correlate). All data are taken from the Human Protein Atlas (https://www.proteinatlas. org/pathology) after analysis by Uhlen et al. [63]. Fragments per kilobase million (FPKM) cut-off (median separation) is set to 1

$F$ connexin expression is favourable for outcome, $U$ connexin expression is unfavourable for outcome, $H$ high expression, $L$ low expression, $n$ number of patients, LUAD lung adenocarcinoma, KIRC kidney renal clear cell carcinoma, KIRP kidney renal papillary cell carcinoma

surrounding skin keratinocytes is significantly correlated with malignant features such as tumour thickness and, in the case of Cx26, metastasis [66]. In lung cancer, the reduced expression of Cx43 mRNA in adjacent normal lung tissue (due to promoter methylation) is significantly correlated with nodal involvement, suggesting that $\mathrm{Cx} 43$ could be a marker for micrometastasis in non-small cell lung cancer [8]. Recently, Cx30.3 (GJB4) mRNA expression was shown to be increased in lung tumours, with the levels in blood buffy coat samples serving as a biomarker for diagnosis and poor prognosis [67]. Mechanistically, Cx30.3 was shown to promote tumour growth and induce chemoresistance via the MET-induced activation of Src.

As shown in Table 1, Cx26 mRNA expression is associated with a poor prognosis in various cancers. For example, high levels of Cx26 mRNA are associated with reduced overall survival in pancreatic cancer $(P<0.001)$ [68]. Microarray analysis (and confirmatory quantitative real-time polymerase chain reaction analysis) of breast cancer samples show the upregulation of Cx26 during progression from ductal carcinoma in situ to invasive ductal carcinoma [69]. At the protein level, Cx26 is detected in the invasive carcinoma foci [69]. In agreement with these findings, Cx26 was recently found to drive CSC selfrenewal in triple-negative breast cancer [62].

At the DNA level, few studies have provided an insight into the role of connexins in cancer. Mutations in $\mathrm{Cx} 43$ have been described in advanced metastatic colon cancer lesions [70]. However, current large-scale genetic studies and analytical tools (e.g. Intogen https://www.intogen.org or COSMIC http://cancer.sanger.ac.uk/cosmic) suggest relatively low mutation rates in connexin-encoding genes and, based on genetic data, none of the 21 connexin genes are classified as tumour suppressors or oncogenes. Nevertheless, individual genetic studies merit follow-up. For example, the C1019T polymorphism in GJA4 (encoding Cx37) is associated with Helicobacter pylori infection in patients with gastric cancer [71]. In glioma, GJB6 (encoding Cx30) was deleted in $25.8 \%$ of the 751 analysed tumours and was mutated in $15.8 \%$ of 158 tumours [51]. However, 
again, the overall patient survival was not correlated with the presence of GJB6 deletions (517 tumours from TCGA and 67 tumours from REMBRANDT) or GJB6 mRNA expression (in patients from TCGA). However, at the protein level, high Cx30 expression adversely influenced the survival (Table 2).

A number of immunohistochemical studies of connexins in cancer-most on Cx26 and Cx43-have described specific prognostic associations. As with mRNA-expression studies, connexin protein expression has been associated with both good and poor prognoses. The studies specifically reporting the significant findings related to patient survival are summarised in Table 2.

In accordance with mRNA-based studies, the expression of different connexins at the protein level can have an opposing prognostic value depending on cancer type, cancer subtype and connexin isoform. For example, in the same breast cancer series, elevated $\mathrm{Cx} 43$ and Cx30 levels have been associated with improved and worse breast cancer outcomes, respectively [64]. Another shared finding between the mRNA and protein studies is the observation that high levels of Cx26 are associated with a poor prognosis in most studies/cancers (Tables 1 and 2). This observation is supported by additional studies evaluating tumour histology or aggressiveness, but not the overall survival, including those of thyroid cancer [72] and bladder cancer [73]. Connexin expression has also been proposed as a diagnostic aid in relation to specific tumour subtypes. In gastric cancer, Cx30 was proposed as a potential marker for an intestinal-type cancer phenotype, and the negative expression of $\mathrm{Cx} 30$ correlates with a more advanced $\mathrm{T}$ grade $(<0.0001), \mathrm{N}$ grade (0.0123) and tumour stage (0.0014) [74]. An association between the expression level of connexins and metastasis can be found for several cancer types. For instance, $\mathrm{Cx} 43$ expression is reduced in primary gastric cancer but increased in matched metastatic lymph nodes [75]. It should also be noted that, in a number of studies, connexin proteins were overexpressed but mislocalised in the cytoplasm. Prominent examples include Cx26 in pancreatic [76] and colon [77] cancer, and Cx43 and Cx32 in prostate cancer [78]. Nuclear $\mathrm{Cx} 43$ has also been reported in a number of tumours (e.g. colon cancer [38] and gliomas [79]). It remains to be seen how this mislocalisation correlates with a recent report showing that nuclear $\mathrm{Cx} 43$ (or the CT alone) can act as a direct nuclear transcription factor that induces the expression of $\mathrm{N}$-cadherin, an important regulator of processes including epithelial-to-mesenchymal transition and cell migration [80].

In summary, connexins are potential prognostic markers in cancer, but a number of limitations need to be addressed before any clinical application. The fact that connexins have both pro- and antitumourigenic properties and are associated with both good and poor prognoses, depending on cancer stage and type/subtype as well as connexin isoform, complicates their clinical applicability. Standardisation is also difficult in terms of reliable antibodies and evaluation parameters such as the quantification of subcellular connexin localisation (e.g. membrane vs cytoplasm), which can significantly influence the prediction of the clinical outcome.

\section{Targeting of connexins in cancer: therapeutic opportunities and challenges}

The complex and multifunctional role of connexins in cancer provides a wide spectrum of therapeutic opportunities and challenges. Increasing numbers of drugs, peptides and RNAi approaches are available to inhibit or enhance GJIC, hemichannel activity or connexin protein-signalling activity. Below, we highlight a selection of in vivo studies demonstrating that the cancer phenotype is altered as a direct consequence of such an experimental targeting of connexins.

\section{Modulation of connexin expression and GJIC}

The restoration of GJIC and/or connexin expression has long been a potential therapeutic strategy. GJIC can be augmented either by enhancing the permeability of existing gap junctions or by increasing the expression of connexins and thereby elevating the number of open gap junction channels [81]. Many fungal and plant-based compounds, as well as an increasing number of synthetic chemical compounds, either increase GJIC or prevent the loss of GJIC in response to cellular exposure to tumour promoters, which is often associated with reduced tumour growth in vivo. Compounds shown to modify connexins or GJIC and affect the tumour phenotype in vivo are summarised in Table 3. It is worth noting that many chemotherapeutic agents also increase connexin expression and/or GJIC [82]. For example, docetaxel increases $\mathrm{Cx} 43$ expression in murine salivary gland carcinoma to reduce tumour growth [83]. This has implications for combinatorial effects in cancer therapy.

However, because connexins under specific conditions can facilitate malignant features, in particular, metastasis or growth of metastases [2], there are situations in which the blockade of GJIC or other functions of connexins may offer distinct therapeutic opportunities. The inhibition of GJIC can be achieved through a number of different mechanisms (Table 3 and recent comprehensive reviews [5, 84]). Despite their non-specificity, many chemical gap junction channel inhibitors have been extensively used, even in vivo. For instance, the GJIC blocker oleamide (a fatty-acid derivative) reduces the formation of pulmonary and hepatic metastatic foci and increases the overall survival of mice injected 


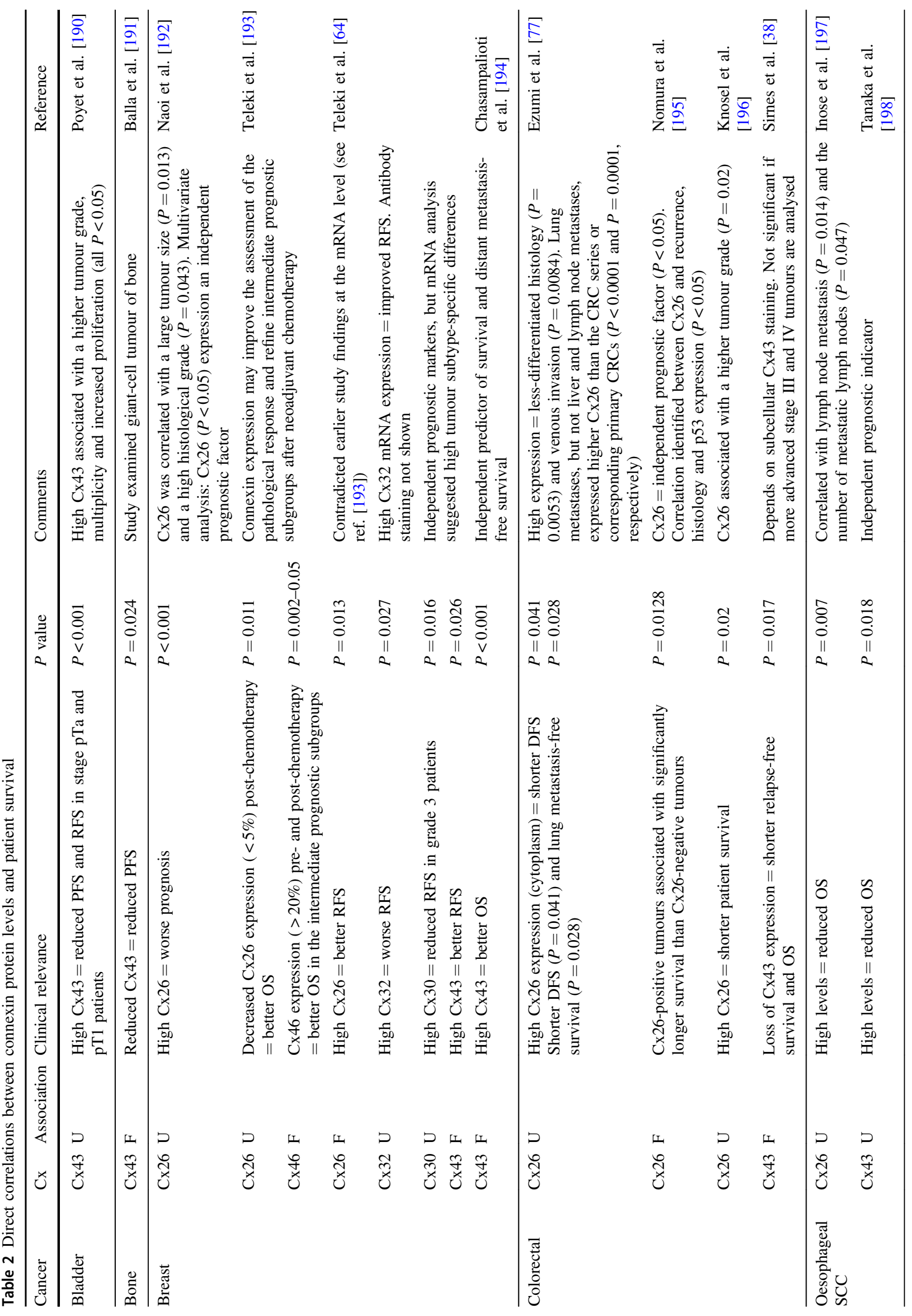




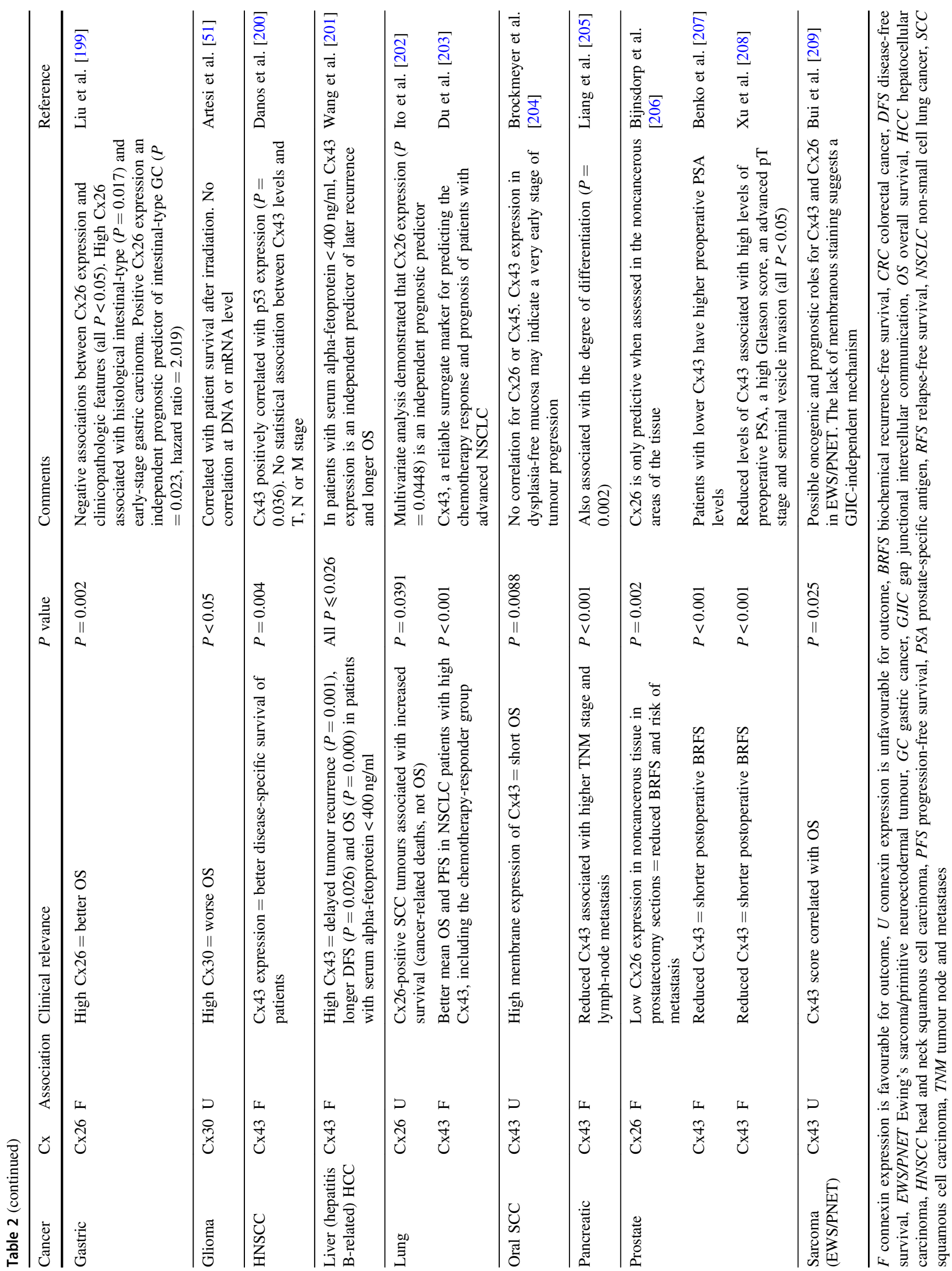




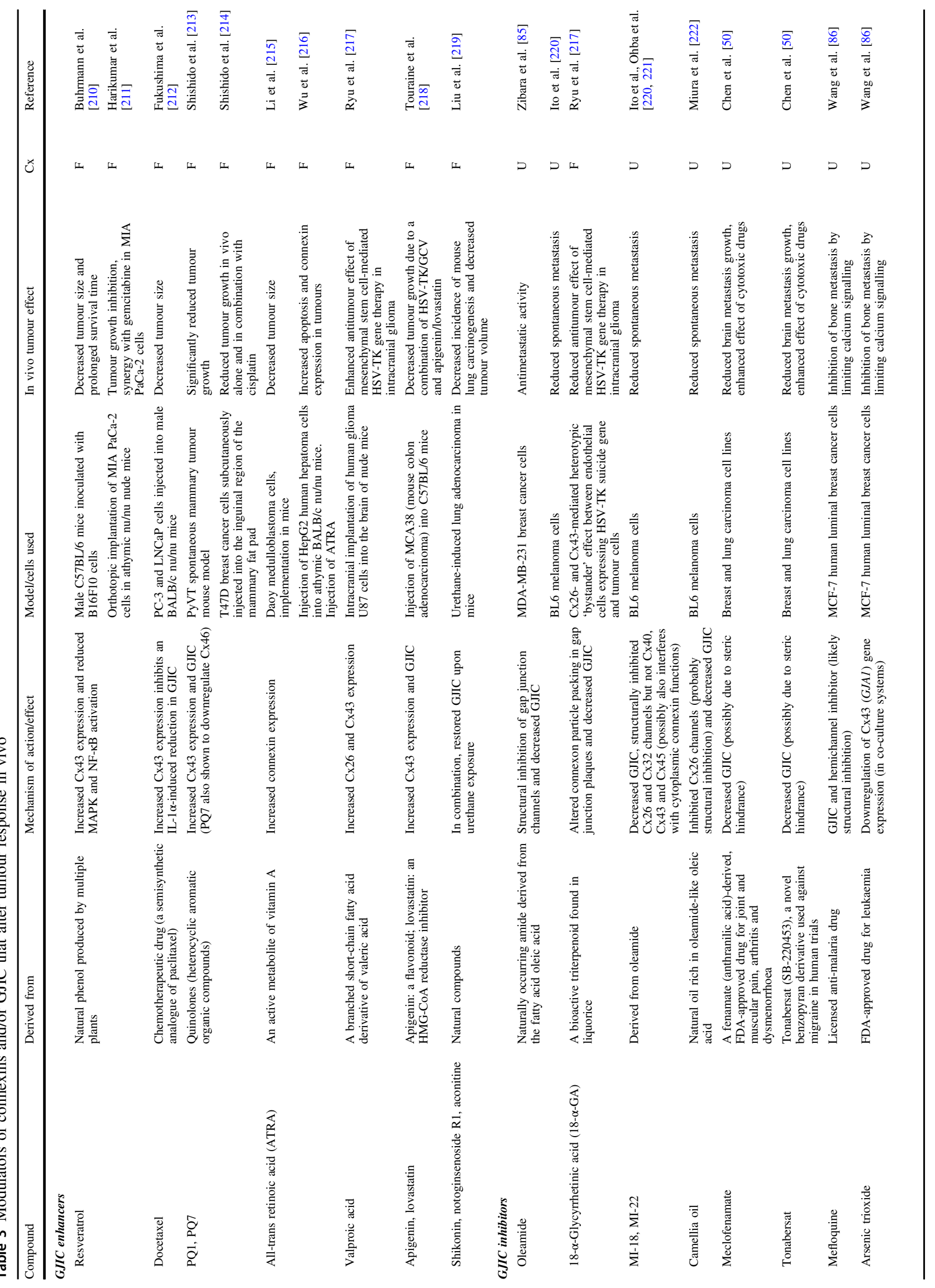




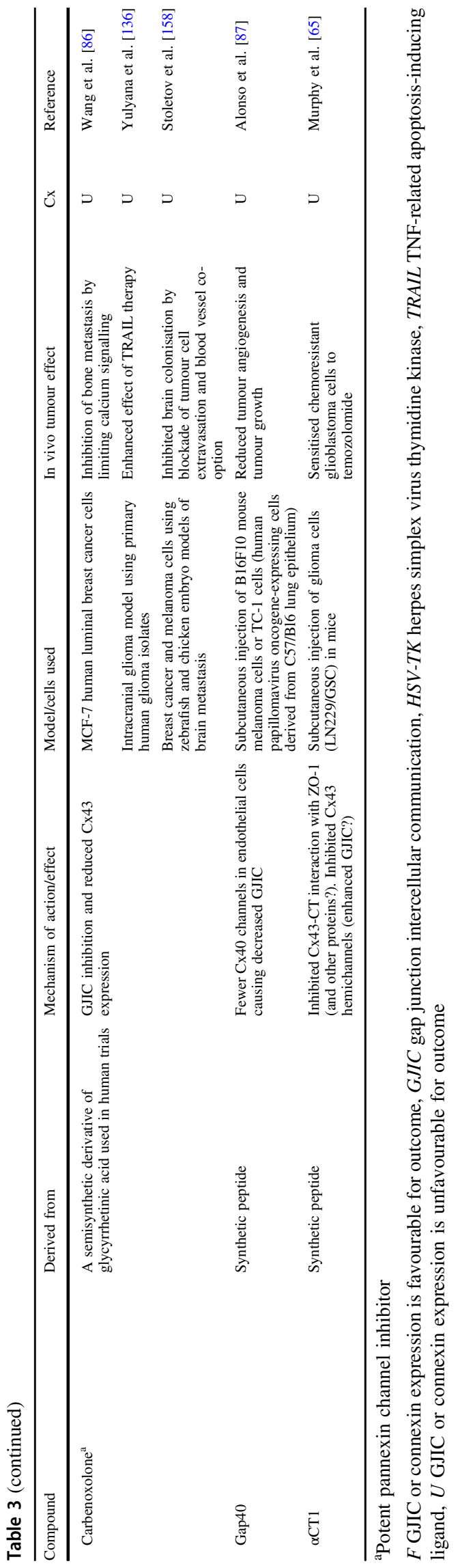

intravenously with MDA-MB-231 breast cancer cells [85]. Mechanistically, oleamide-induced loss of heterologous GJIC between tumour cells and endothelial cells was suggested to interfere with cancer-cell extravasation. Using a brain metastasis mouse model, Massagué and colleagues recently demonstrated the potent growth inhibition of brain metastases from breast and lung cancer cells in response to blockade of heterologous GJIC between the cancer cells and astrocytes [50]. Inhibition of heterologous GJIC was achieved either by the knockdown of Cx43 expression or by the use of the gap junction channel inhibitors tonabersat or meclofenamate, which pass the blood-brain barrier [50]. Tonabersat has been used as a migraine prophylaxis drug, whereas meclofenamate is an FDA-approved anti-inflammatory drug for oral administration. Mechanistically, these GJIC inhibitors seem to inhibit tumour growth by blocking a cGAMP-mediated signalling cascade that orchestrates paracrine signalling between host and tumour cells [50]. Consequently, as the first cancer clinical trial in which GJIC is specifically being targeted, meclofenamate is being tested in human patients with recurrent or progressive brain metastasis (https://clinicaltrials.gov/ct2/show/NCT02429570?id= NCT02429570\&rank=1\&load=cart). Recently, a novel role of Cx43-based gap junctions was also identified in breast cancer bone metastasis [86]. Gap junctions were found to mediate calcium flow from osteogenic cells to the cancer cells. Blocking such heterocellular intercellular calcium transfers from the osteogenic niche to cancer cells, by gap junction inhibitors (carbenoxelone and arsenite trioxide) or by the ablation of $\mathrm{Cx} 43$ in either the osteogenic cells or the cancer cells, prevented bone metastasis progression in mice [86].

Thus, many of the studies reporting the inhibitory effects on tumour growth upon inhibition of GJIC mechanistically relate this effect to a loss of heterologous GJIC between tumour cells and cells in their microenvironment (as reviewed in $[50,85]$ and discussed elsewhere in this manuscript). Other successful strategies include the peptidemediated inactivation of $\mathrm{Cx} 40$ in endothelial cells causing the inhibition of tumour angiogenesis in vivo and subsequently decreased tumour growth [87] (see Table 3 and section "Emerging concepts"). $\alpha \mathrm{CT} 1$, a peptide that blocks ZO-1 and potentially other proteins from interacting with the Cx43-CT (see section "Targeting of connexins in cancer"), has been demonstrated to prevent temozolomide resistance in human glioblastoma cell lines [65]. The use of peptides arguably provides for a more specific targeting compared with the more general chemical GJIC inhibitors and may reduce potential adverse effects. Cx43-blocking antibodies also reduce tumour growth in murine models. Notably, the intravenous administration of a monoclonal antibody targeting the second extracellular loop of $\mathrm{Cx} 43$ reduces glioma growth and survival of experimental 
animals when used alone [88] or in combination with standard cancer therapy approaches [89]. The same antibody has been used as a guidance system to deliver diagnostic markers or therapeutic compounds, such as cisplatin, to $\mathrm{Cx} 43$-positive high-grade gliomas $[90,91]$.

\section{Targeting of hemichannels}

Connexin hemichannels are normally closed but, when activated, they can release autocrine and paracrine signals, such as $\mathrm{NAD}^{+}$, glutamate or ATP, that can affect cell proliferation and survival [92]. For instance, ATP release activates the AKT/AMPK/mTOR signalling pathway, thus linking hemichannel activity with cell proliferation and survival [93]. Several lines of evidence suggest that Cx43 hemichannels are involved in promoting tumour growth. Antibodies against the second extracellular loop domain of Cx43, which blocks hemichannels [94], reduce glioma tumours generated with C6 cells in rats [89]. Similarly, the peptide $\alpha \mathrm{CT} 1$ increases the sensitivity to chemotherapy in glioma cells, possibly through the inhibition of $\mathrm{Cx} 43$ hemichannel activity [65]. On the other hand, Cx43 hemichannels in osteoblast bone cells may provide an intrinsic self-defence mechanism against breast cancer metastasis [95]. Among the other molecules released by $\mathrm{Cx} 43$ hemichannels in osteoblasts, ATP acts as a paracrine signal that triggers an inflammatory cascade to inhibit the migration, invasion and anchorage-independent growth of breast cancer cells [96]. Consequently, the antibody blockade of osteocyte $\mathrm{Cx} 43$ hemichannels increases bone metastasis in mice [95]. Collectively, these data suggest that Cx43 hemichannel activity in healthy tissue cells may have a beneficial effect by preventing metastasis, whereas hemichannels in tumour cells may favour their growth.

\section{Targeting of the connexin interactome}

Connexins interact with a wide variety of proteins that, independent of channel activity, can affect cancer cell phenotype, including cell growth, migration and differentiation (Fig. 3; recently reviewed in refs. [97, 98]). Strategies that mimic, promote or disrupt some of these specific interactions could be used in cancer therapy. The fact that $\mathrm{Cx} 43-\mathrm{CT}$ is a disordered region favours the use of mimetic peptides that can restore or interfere with its functions. In tumour cells with low levels of $\mathrm{Cx} 43$, the restoration of Cx43 function may reduce cell proliferation. In glioma cells, this occurs via the inhibition of the oncogenic activity of c-Src [99]. The mechanism by which $\mathrm{Cx} 43$ reduces c-Src activity resides in a short region of Cx43-CT (266-283) that acts as a docking platform for c-Src together with its endogenous inhibitors PTEN and CSK [43]. Notably, the mimetic peptides of this region fused to the TAT- penetrating sequences (TAT-Cx $43_{266-283}$ ) can mimic the anti-oncogenic effect of $\mathrm{Cx} 43$ in glioma cells such as primary GSCs $[55,100]$.

In contrast, some proteins may favour cell growth or migration upon interaction with $\mathrm{Cx} 43-\mathrm{CT}$. For instance, Cx43 may interact with $\mathrm{p} 21$-activated protein kinase 1 , which activates the MAPK p38 to increase the migration of HeLa cells [101], or may compete with tubulin-Smad $2 / 3$ interaction causing Smad2/3 release [102] (Fig. 3). Other $\mathrm{Cx} 43$-interaction partners regulate the $\mathrm{Cx} 43$ protein level or subcellular localisation. Disruption of these interactions may have therapeutic potential. $\alpha \mathrm{CT} 1$ is a Cx43-CT mimetic peptide that comprises the ZO-1 PDZ-binding domain of $\mathrm{Cx} 43$ fused to a cell-penetration sequence, which was designed as a tool to disrupt the interaction between endogenous ZO-1 and Cx43 [103]. Consequently, $\alpha \mathrm{CT} 1$ can increase the size of $\mathrm{Cx} 43$ gap junction plaques and increase GJIC to the detriment of hemichannel activity [104]. $\alpha \mathrm{CT} 1$ increases the sensitivity of glioma cells to temozolomide [65] and of breast cancer cells to tamoxifen and lapatinib [105]. In an ongoing clinical trial in dogs with naturally occurring high-grade glioma, a slow controlled release of $\alpha \mathrm{CT} 1$ encapsulated in a polymer is being tested in combination with chemotherapy [106].

\section{Enhanced and synergistic therapeutic effects of connexin targeting}

\section{The bystander effect: kiss-of-life or kiss-of-death?}

The bystander effect underpins a key therapeutic strategy in anticancer approaches and significantly enhances suicide gene therapy strategies [107]. A well-established suicide gene therapy approach involves the viral transduction of the herpes simplex virus (HSV) thymidine kinase (TK) gene into cancer cells [108]. The viral TK enzyme phosphorylates the nucleoside analogue ganciclovir (GCV), which causes chain termination during DNA replication and leads to tumour cell death. Many reports in the 1990s revealed that neighbouring tumour cells that were not transduced with the TK/GCV suicide system also died. This was demonstrated in vitro and in vivo to be due to the GJICmediated transfer of activated GCV and/or other toxic metabolites [109, 110]. This led to the hypothesis that the induction of connexin expression or re-establishment of GJIC might potentiate the bystander effect [111], a claim substantiated early on, both in vitro $[109,112]$ and in vivo [113]. This theory is supported by many studies (e.g. refs. [114-117]), including a recent one in breast cancer [118] and liver cancer, in which the co-expression of $\mathrm{Cx} 43$ and SUMO1 in liver CSCs increased GJIC and their sensitivity to HSV-TK/GCV therapy in vitro and in vivo [57]. However, other studies reported no evidence for a GJIC- 
mediated bystander effect [119]. Moreover, GJIC can protect transduced cells from the toxic active GCV by allowing effective drug dilution throughout the cell, preventing cell death in a so-called "Good Samaritan" effect [120, 121].

The bystander effect is important in a wide range of circumstances other than suicide gene therapy. Notably, some chemotherapeutic drugs or radiation-induced metabolites such as DNA damage-induced sensing/signalling molecules or cytoplasmic irradiation responders (reactive oxygen species, reactive nitrogen species, $\mathrm{Ca}^{2+}$ and cytokines) can also transmit through GJIC, inducing a bystander effect [120]. However, the strength and type of the signal may have distinct and opposing effects: (1) toxic signals kill neighbouring cells (which may be tumour cells or healthy cells) or (2) toxic signals are diluted into neighbouring cells, favouring the survival of the targeted cells. Importantly, this implicates GJIC in coordinating cellular and tissue responses to carcinogens, radiation and chemotherapies and leads to the possible strategies (via both enhanced or blocked GJIC) for either protecting undamaged non-targeted cells against such signals or potentiating the signals in order to kill tumour cells. Application of this knowledge to other aspects of connexin cancer biology is important.

\section{Need for combinatorial therapy}

Within the field of cancer therapy, there is a general consensus on the need for rational combinatorial targeted therapy. Synergistic effects on cancer cell growth as a result of enhanced connexin expression or GJIC in combination with drugs targeting other cellular processes have been described in many studies [122-127] (Table 3). For instance, kanglaite, a natural plant seed compound that upregulates $\mathrm{Cx} 43$ expression, sensitises colorectal cancer cells to Taxol [124]. Simvastatin (a statin) induces GJIC and enhances the effect of platinum-based chemotherapeutic drugs [126]. In addition, protection can be provided against the non-desired cytotoxic effects of cisplatin on healthy cells, including reproductive testicular Sertoli cells [127]. Such dual kiss-of-life/kiss-of-death bystander effects can contribute to the overall chemotherapeutic outcome on multiple levels. It also poses a therapeutic challenge. The putative positive and negative effects such therapies can provide in relation to tumour growth must therefore be carefully assessed in order to avoid a possible worsening rather than an improvement of the clinical outcome.

The therapeutic response of cancer cells can also be affected by the direct overexpression of connexins, in an isoform-specific manner. For instance, Cx43 overexpression can enhance the sensitivity to common chemotherapeutic drugs such as doxorubicin, fluorouracil and oxaliplatin in human gastric cancer cells [128], etoposide, paclitaxel and doxorubicin in glioma cells [129], and artesunate in MCF-7 breast cancer cells [130]. Cx32 potentiates the cytotoxicity of vinblastine and Src inhibitors in renal cell carcinoma cells [131], whereas Cx26 increases the effect of cisplatin in human bladder cancer cells [132] and of doxorubicin in prostate cancer cells [133]. Both channel-dependent and -independent mechanisms have been suggested to underlie this effect [130, 134].

In other contexts, connexins can have an inverse effect with respect to drug sensitivity. Reduced $\mathrm{Cx} 43$ expression is associated with increased drug sensitivity in glioma cells $[52,134-136]$, whereas the upregulation of Cx26 is associated with gefitinib resistance in lung cancer cells [137]. The specific inhibition of Cx46-mediated GJIC in GSCs attenuates proliferation, self-renewal and tumour growth and synergises with temozolomide to induce apoptosis [138]. There is also in vivo evidence to support this dichotomy in relation to therapeutic efficacy. For instance, shRNA-mediated knockdown of Cx43 or inhibition of GJIC by meclofenamate and tonabersat strongly potentiates the effect of carboplatin-based chemotherapy on brain metastases from breast and lung carcinoma cells [50]. Moreover, the efficacy of tumour necrosis factor-related apoptosisinducing ligand therapy is enhanced when combined with the GJIC inhibitor carbenoxolone in an intracranial glioma model [136]. The combined use of tumour necrosis factorrelated apoptosis-inducing ligand and carbenoxolone could offer a favourable alternative for the treatment of glioma, particularly considering the low cytotoxic nature of carbenoxolone. Notably, carbenoxolone, as well as peptides targeting Cx43, attenuates cancer-induced bone pain [139], highlighting another facet of cancer care in which connexins can be further explored.

\section{Emerging concepts}

\section{Role of connexins in tumour microenvironment}

That GJIC between normal cells and tumour cells (heterologous GJIC) can inhibit the growth of tumour cells was shown in the mid 1980s by Loewenstein and colleagues [140]. This phenomenon has since been demonstrated in many cancer types and model systems, as recently reviewed [141]. Heterologous GJIC between tumour cells and the cells within their microenvironment (Fig. 4) has been linked to both positive and negative effects on tumour progression and therapy resistance.

\section{Communication between cancer cells and immune cells}

Tumour cells deliver antigenic peptides through gap junctions to dendritic cells, and this cross-presentation is associated with enhanced immune-mediated tumour elimination. 


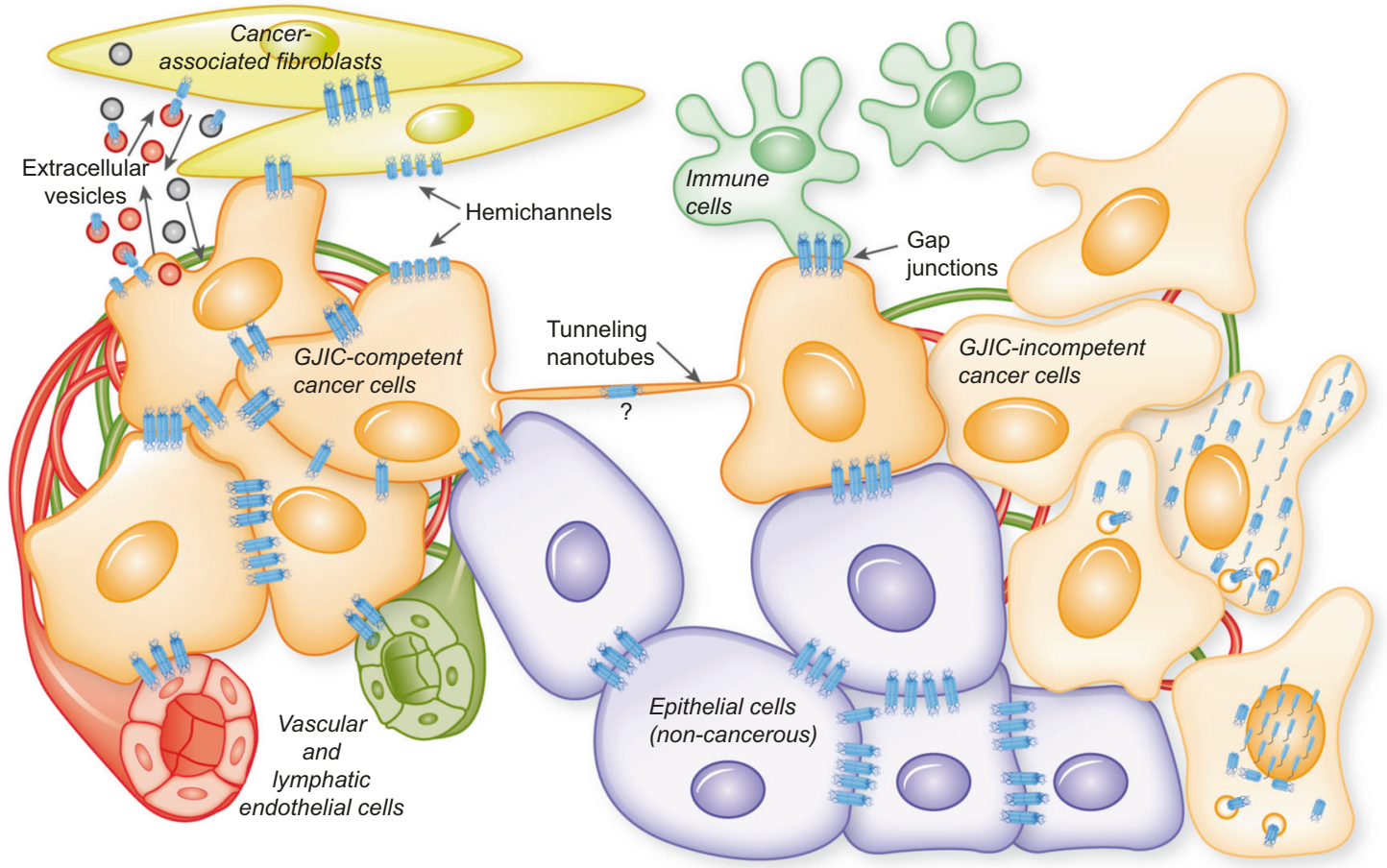

Fig. 4 Connexins and the tumour stroma. GJIC can occur between cancer cells or in a heterocellular manner between cancer cells and nearby cells such as noncancerous epithelial tissue cells and stromal cells, including cancer-associated fibroblasts, immune cells and vascular and lymphatic endothelial cells. In addition, there is crosstalk via the hemichannel release of autocrine and paracrine signals. These signals influence tumour growth both positively and negatively in a context-dependent manner and help to regulate apoptosis, proliferation, invasion, intravasation and extravasation. In addition, connexins are thought to be implicated in other communication forms, as a part of

Presentation of antigenic peptides between melanoma cells and dendritic cells increases the melanoma-specific T-cell response [142]. The infection of melanoma tumours with Salmonella bacteria induces $\mathrm{Cx} 43$ expression, which enhances the antigen presentation into infiltrating dendritic cells, activating an antitumour response [143]. Cx43-mediated GJIC may also improve the immune surveillance of tumours via the activation of natural killer cells [144, 145]. GJIC-mediated transfer of miRNAs from immune cells to hepatocarcinoma cells seems to inhibit tumour growth [146]. These studies (and others, as reviewed recently [141]) are of particular interest in relation to immunotherapy and tumour vaccines [141]. Connexins also regulate many other functions within the immune and lymphatic systems, which awaits an additional analysis [147].

\section{Angiogenesis and communication between cancer cells and endothelial cells}

Angiogenesis, the formation of new capillaries from preexisting blood vessels, is required for cancer progression tunnelling nanotubes (microtubes) or extracellular vesicle function (e.g. exosomes). Other tumours, or parts of tumours, are devoid of GJIC and may or may not express connexins at high levels in the cytoplasm or nucleus, thus escaping the direct GJIC with surrounding cells. This may be associated with a reduced polarity and cell-cell adhesion. The benefits and drawbacks of maintained GJIC are likely tissue and stage dependent. An understanding of this complex network of signals is essential to move forward with additional therapeutic strategies of targeting connexins in cancer. GJIC, gap junction intercellular communication

[148]. Overexpression of Cx43 in melanoma and breast cancer cells suppresses tumour angiogenesis [28, 149]. In accordance with these findings, Cx43 knockdown in melanoma cells increases vessel density [149]. The silencing of Cx43 in breast cancer cells results in increased vascular endothelial growth factor expression and decreased thrombospondin expression [29]. In contrast, the overexpression of $\mathrm{Cx} 26$ or $\mathrm{Cx} 43$ in breast cancer cells is associated with the upregulation and secretion of IL-6 and MCP-1, which inhibit endothelial cell tube formation in vitro and tumour vascularisation in vivo [28].

Endothelial connexins also play important roles in tumour angiogenesis. The knockdown of endothelial Cx37, Cx40 or Cx43 or the pharmacologic inhibition of GJIC diminishes the angiogenic sprouting of endothelial cells in in vitro studies [150]. A recent work using a combination of different in vitro, ex vivo and in vivo models has shown that targeting of endothelial Cx40 decreases tumour growth by reducing angiogenesis and improving vessel perfusion [87]. This was demonstrated both in mouse endothelial-specific Cx40 knockout models and by the injection of the specific 
peptide ${ }^{40} \mathrm{Gap} 27$ that binds to the extracellular loop of $\mathrm{Cx} 40$ and blocks channel activity [151].

Because endothelial and myoendothelial gap junctions are fundamentally important for a coordinated vessel response over longer distances [152, 153], a therapeutic approach focused on vascular connexins would be conceivable through the specialised targeting of tumour vessels in combination with anti-angiogenic strategies.

There is also evidence of direct communication between tumour cells and endothelial cells (Fig. 4). Recent studies have demonstrated GJIC-mediated heterotypic exchange of microRNAs between cancer cells and endothelial cells. Notably, endothelial cells deliver miR-145-5p to colon cancer cells via gap junctions, causing the upregulation of Cx43 expression and reduced angiogenesis [154]. Moreover, the inhibition of GJIC by carbenoxolone blocks the interchange of specific cancer-associated microRNAs between human microvascular endothelial cells and a human glioma cell line [155].

As mentioned, Cx26 may facilitate extravasation into the endothelium during metastasis [47], and $\mathrm{Cx} 43$ enhances attachment and diapedesis into endothelial cells in models of breast cancer [48, 156] and melanoma metastasis [157]. Heterocellular Cx43-mediated GJIC between gastric cancer cells and mesothelial cells may facilitate diapedesis during peritoneal metastasis [75]. Using zebrafish and chicken embryo models of brain metastasis, Stoletov et al. [158] determined that $\mathrm{C} \times 26$ and $\mathrm{C} \times 43$ acted in the early initiation stages of metastatic lesion formation in association with vasculature. RNAi-mediated depletion of $\mathrm{Cx} 26$ and $\mathrm{Cx} 43$ in melanoma and breast cancer cells, respectively, or pharmacological inhibition of GJIC using carbenoxolone, was found to inhibit brain colonisation by blocking tumour cell extravasation and blood vessel co-option [158]. Such crosstalk between cancer cells and blood vessels may also occur via hemichannels, such as the one through ATP release, which ultimately can stimulate angiogenesis [159]. There is also evidence that GJIC facilitates cancer cell migration through the lymphatic endothelium [160]. Thus, blockade of connexin-mediated heterocellular communication is emerging as a potential viable strategy for reducing metastasis. Indeed, the $\mathrm{Cx} 43$ channel blocker oleamide has antimetastatic properties in the MDA-MB-231 breast cancer cell line, presumably due to the inhibition of extravasation into the endothelium [85].

\section{Communication between cancer cells and astrocytes}

Connexins can also elicit pro-tumourigenic effects in brain tumours. Cx43 expression and heterologous GJIC between malignant glioma cells and reactive astrocytes enhance cell invasion into the brain parenchyma [161-163], which may in part occur through microRNA-mediated signalling [164].
Glioma cells can also become more resistant to chemotherapy- or radiotherapy-induced cell death through both homocellular and heterocellular GJIC pathways [51, 53, 165], as well as via Cx43-specific GJIC-independent mechanisms [166]. GJIC between reactive astrocytes and melanoma cells protects against chemotherapy through the sequestration of calcium [34]. A recent study has described another signalling network between astrocytes and breast and lung carcinoma cells involving cGAMP and the stimulator of interferon genes (STING) pathway (see section "Modulation of connexin expression and GJIC"), and the inhibition of GJIC or Cx43 expression was found to substantially reduce the brain metastatic burden and enhance chemotherapy efficacy [50]. In summary, GJIC between tumour cells and astrocytes promotes colonisation, resistance to chemotherapy and survival of tumour cells in the brain [34, 50, 164, 167]. Targeting of this axis may provide clinical benefits.

\section{Connexins and tumour viruses}

An estimated $10-12 \%$ of human cancers worldwide are caused by viruses and $4.5 \%$ are caused by the so-called "high-risk" human papillomaviruses (HPVs) [168]. Rous sarcoma virus-infected fibroblasts display a loss of GJIC, and its oncogene pp $60^{\mathrm{v}-\mathrm{src}}$ causes $\mathrm{Cx} 43$ tyrosine phosphorylation and reduced Cx43 levels [169]. Similarly, SV40 large $\mathrm{T}$ antigen-transformed normal invasive trophoblasts lose GJIC and display reduced Cx43 levels [169]. Human cytomegalovirus is not recognised as a tumour virus. However, human cytomegalovirus proteins have been detected at high levels in gliomas and can downregulate Cx43 and GJIC [170]. These data suggest that a range of viruses inhibit GJIC.

In 1969, McNutt and Weinstein recognised that gap junction plaques are lost in cervical cancers [171]. Subsequently, cervical cancers were shown to be caused by HPVs [172]. Reduced connexin expression can occur in preneoplastic cervical lesions [173], perhaps in part due to the loss of epithelial differentiation. On the other hand, loss of Cx43-mediated GJIC occurs as a direct consequence of HPV-associated cancer progression [174], and HPV infections alter multiple connexins at the transcript level [175]. High-risk HPVs encode two oncoproteins, E6 and E7, which are highly expressed in cervical cancer. E6 alters Cx43 trafficking to the plasma membrane either through its ability to alter cell signalling pathways or through its interaction with the Cx43 partner protein Dlgh1 [42, 176]. HPV E5, a subsidiary oncoprotein, also downregulates Cx43 and GJIC when overexpressed in keratinocytes [177].

Upon infection, viral DNA is detected by cyclic GMPAMP synthase, which synthesises the STING activator cGAMP to induce an antiviral state through intercellular 
transmission. Connexins are responsible for the bystander immunity to viruses [178], and so viruses may have evolved means to inactivate this response by regulating connexins, a feature that could be exploited therapeutically.

\section{Role of connexins in long-distance cell-cell communication}

\section{Tunnelling nanotubes}

Tunnelling nanotubes (TNTs) are thin actin-based membrane bridges that connect cells over distances of up to several cell diameters [179]. These structures allow for the intercellular transfer of microRNAs, proteins and cytoplasmic organelles, including mitochondria. The presence of connexin channels interposed in the nanotube connections permits long-distance electrical coupling between cells $[179,180]$. TNTs are formed between various cancer cell types in vitro [179]. TNTs between malignant cells and stromal cells may be involved in chemoresistance [181] and tumour-stromal crosstalk [182, 183]. Recently, Osswald et al. [184] demonstrated in vivo that glioma cells form a network of TNT-like structures called microtubes that contribute to their invasion in the brain. Cx43-containing gap junctions within this network were suggested to turn the tumour into a syncytium of interconnected cells that is highly resistant to radiation therapy, presumably by distributing calcium between cells to prevent apoptosis upon radiation-induced release of intracellular calcium [184].

\section{Extracellular vesicles}

Extracellular vesicles (EVs), which constitute microvesicles, apoptotic bodies and exosomes, are membranebased structures that can carry and deliver bioactive molecules, including proteins and nucleic acids, from one cell to another. This form of cell-to-cell communication can occur over very long distances and efficiently cross the bloodbrain barrier. EVs released by tumour cells and cancerassociated fibroblasts affect cancer progression by transferring molecules influencing tumour initiation, angiogenesis, metastasis and drug resistance [185]. Functional Cx43 channels were recently identified in the membrane of EVs [186]. In melanoma, Cx32, Cx43 and Cx45 were detected in these structures [187]. Connexins facilitate the transfer or exchange of EV contents with target cells, possibly by improving fusion events with cells [186]. This may be exploited therapeutically to improve drug delivery. However, in one mouse model, delivery of doxorubicin as a chemotherapeutic agent was not improved in the presence of Cx43 in EVs, although it strikingly reduced cardiotoxicity [188]. In addition, Cx43 phosphorylation through extracellular signal-regulated kinase signalling induces exosome release upon traumatic brain injury [189]. Thus, it seems clear that connexins are involved in the formation and function of EVs, but the therapeutic implications await further works.

\section{Concluding remarks and future perspectives}

Substantial knowledge on how gap junctions contribute to cancer has accumulated since the seminal work by Loewenstein and Kanno demonstrated a loss of electrical coupling in liver cancer more than 50 years ago [7]. Connexins predict the prognosis of a number of cancers, although the lack of established protocols and confirmatory independent studies has limited their clinical utility. Several promising studies using an expanded set of tools to modulate connexin or gap junction function have demonstrated potent antitumoral effects. As we decipher their cancer type- and stage-specific roles, significant progress towards targeting of connexins and gap junctions in a patient-specific therapeutic setting can be expected. An ongoing clinical trial testing the GJIC inhibitor meclofenamate in patients with carcinoma metastasis to the brain underpins this positive outlook (https://clinicaltrials.gov/ct2/show/NCT02429570? $\mathrm{id}=$ NCT02429570\&rank $=1 \&$ load $=$ cart). Nevertheless, there are significant challenges that remain to be addressed. The fact that connexins can be both anti- and protumorigenic is of particular concern. For example, would enhancing GJIC or connexin expression in a primary tumour run a risk of more efficient metastatic spread or growth? Does inhibition of GJIC in patients with metastasis increase the risk of further tumour dissemination or reactivated tumour growth in sites harbouring dormant tumour cells? Currently, this clinical problem can only be addressed by hypothetical risk assessment and thus further research, including an extensive use of in vivo models and a careful follow-up of ongoing clinical trials, is required.

Currently, only a few of the 21 connexin isoforms have been characterised in terms of their role in cancer. Additional studies are necessary to elucidate the GJIC-dependent and -independent mechanisms by which the various connexins positively or negatively affect cell growth, differentiation, invasion and other important cancer-associated features. In this context, more specific tools will be required to target the different functions of connexins. Further efforts need to be devoted to the identification of more specific connexin inhibitors. The use of specific peptides and peptidomimetics have shown a great promise towards this. However, their side effects must be carefully addressed (particularly if applied systemically) due to the critical functions of several connexins in various organs. Another important challenge will be to dissect the molecular basis of the regulation of the various connexin isoforms at the 
transcriptional, translational and post-translational levels and to define how the dysregulation of these processes contributes to aberrant levels or subcellular localisation of connexins during various stages of cancer progression. The identification of solutions to these research challenges will set the stage for new diagnostic and therapeutic advances.

Acknowledgements The authors are members of The European Consortium for Research on Connexins and Cancer. We apologise to authors whose work could not be cited due to space limitations. Trond Aasen acknowledges the support from Instituto de Salud Carlos III (grants PI16/00772 and CPII16/00042), co-financed by the European Regional Development Fund (ERDF). Edward Leithe acknowledges the support from the Norwegian Cancer Society (grant number 709125), the South-Eastern Norway Regional Health Authority (grant number 2016013) and the Kristian Gerhard Jebsen Foundation. Arantxa Tabernero acknowledges the support from the Ministerio de Economía y Competitividad, Spain; FEDER BFU2015-70040-R, Consejería de Educación, Junta de Castilla y León, Spain; FEDER SA026U16 and Fundación Ramón Areces. María D Mayán acknowledges the support from the Spanish Foundation for Research on Bone and Mineral Metabolism (FEIOMM), grant PRECIPITA-2015-000139 from the FECYT-Ministerio de Economía y Competitividad, grant IN607B 2017/21 from Xunta de Galicia and grant PI16/00035 from the Instituto de Salud Carlos III (ISCIII, Spain), and the European Regional Development Fund, 'A way of making Europe' from the European Union. Sheila Graham acknowledges the support from Worldwide Cancer research grant 08-0159 and from the Medical Research Council as core funding for the MRC University of Glasgow Centre for Virus Research. Marc Mesnil acknowledges the support from Ligue contre le Cancer (Comités de la Charente-Maritime et de la Vienne).

\section{Compliance with ethical standards}

Conflict of interest The authors declare that they have no conflict of interest.

Publisher's note: Springer Nature remains neutral with regard to jurisdictional claims in published maps and institutional affiliations.

Open Access This article is licensed under a Creative Commons Attribution 4.0 International License, which permits use, sharing, adaptation, distribution and reproduction in any medium or format, as long as you give appropriate credit to the original author(s) and the source, provide a link to the Creative Commons license, and indicate if changes were made. The images or other third party material in this article are included in the article's Creative Commons license, unless indicated otherwise in a credit line to the material. If material is not included in the article's Creative Commons license and your intended use is not permitted by statutory regulation or exceeds the permitted use, you will need to obtain permission directly from the copyright holder. To view a copy of this license, visit http://creativecommons. org/licenses/by/4.0/.

\section{References}

1. Laird DW. Life cycle of connexins in health and disease. Biochem J. 2006;394:527-43.

2. Aasen T, Mesnil M, Naus CC, Lampe PD, Laird DW. Gap junctions and cancer: communicating for 50 years. Nat Rev Cancer. 2016;16:775-88.
3. Saez JC, Leybaert L. Hunting for connexin hemichannels. FEBS Lett. 2014;588:1205-11.

4. Mesnil M, Aasen T, Boucher J, Chepied A, Cronier L, Defamie $\mathrm{N}$, et al. An update on minding the gap in cancer. Biochimica et Biophysica Acta. 2018;1860:237-43.

5. Laird DW, Lampe PD. Therapeutic strategies targeting connexins. Nat Rev Drug Discov. 2018;17:905-21.

6. Delvaeye T, Vandenabeele P, Bultynck G, Leybaert L, Krysko DV. Therapeutic targeting of connexin channels: new views and challenges. Trends Mol Med. 2018;24:1036-53.

7. Loewenstein WR, Kanno Y. Intercellular communication and the control of tissue growth: lack of communication between cancer cells. Nature. 1966;209:1248-9.

8. Chen JT, Cheng YW, Chou MC, Sen-Lin T, Lai WW, Ho WL, et al. The correlation between aberrant connexin 43 mRNA expression induced by promoter methylation and nodal micrometastasis in non-small cell lung cancer. Clin Cancer Res. 2003;9:4200-4.

9. Chen Y, Huhn D, Knosel T, Pacyna-Gengelbach M, Deutschmann N, Petersen I. Downregulation of connexin 26 in human lung cancer is related to promoter methylation. Int $\mathrm{J}$ Cancer. 2005;113:14-21.

10. Sirnes S, Honne H, Ahmed D, Danielsen SA, Rognum TO, Meling GI, et al. DNA methylation analyses of the connexin gene family reveal silencing of GJC1 (Connexin45) by promoter hypermethylation in colorectal cancer. Epigenetics. 2011;6:602-9.

11. Tan LW, Bianco T, Dobrovic A. Variable promoter region $\mathrm{CpG}$ island methylation of the putative tumor suppressor gene Connexin 26 in breast cancer. Carcinogenesis. 2002;23:231-6.

12. Jin Z, Xu S, Yu H, Yang B, Zhao H, Zhao G. miR-125b inhibits Connexin43 and promotes glioma growth. Cell Mol Neurobiol. 2013;33:1143-8.

13. Li X, Pan JH, Song B, Xiong EQ, Chen ZW, Zhou ZS, et al. Suppression of CX43 expression by miR-20a in the progression of human prostate cancer. Cancer Biol Ther. 2012;13:890-8.

14. Smyth JW, Shaw RM. Autoregulation of connexin43 gap junction formation by internally translated isoforms. Cell Rep. 2013;5:611-8.

15. Salat-Canela C, Sese M, Peula C, Ramon y Cajal S, Aasen T. Internal translation of the connexin 43 transcript. Cell Commun Signal. 2014;12:31.

16. Ul-Hussain M, Olk S, Schoenebeck B, Wasielewski B, Meier C, Prochnow N, et al. Internal ribosomal entry site (IRES) activity generates endogenous carboxyl-terminal domains of $\mathrm{Cx} 43$ and is responsive to hypoxic conditions. J Biol Chem. 2014;289:20979-90.

17. James CC, Zeitz MJ, Calhoun PJ, Lamouille S, Smyth JW. Altered translation initiation of Gja1 limits gap junction formation during epithelial-mesenchymal transition. Mol Biol Cell. 2018;29:773-880.

18. Lampe PD, Lau AF. The effects of connexin phosphorylation on gap junctional communication. Int $\mathrm{J}$ Biochem Cell Biol. 2004;36:1171-86.

19. Leithe E. Regulation of connexins by the ubiquitin system: Implications for intercellular communication and cancer. Biochim Biophys Acta. 2016;1865:133-46.

20. Eghbali B, Kessler JA, Reid LM, Roy C, Spray DC. Involvement of gap junctions in tumorigenesis: transfection of tumor cells with connexin $32 \mathrm{cDNA}$ retards growth in vivo. Proc Natl Acad Sci USA. 1991;88:10701-5.

21. Mesnil M, Krutovskikh V, Piccoli C, Elfgang C, Traub O, Willecke K, et al. Negative growth control of HeLa cells by connexin genes: connexin species specificity. Cancer Res. 1995;55:629-39.

22. Qin H, Shao Q, Curtis H, Galipeau J, Belliveau DJ, Wang T, et al. Retroviral delivery of connexin genes to human breast 
tumor cells inhibits in vivo tumor growth by a mechanism that is independent of significant gap junctional intercellular communication. J Biol Chem. 2002;277:29132-8.

23. Zhang YW, Morita I, Ikeda M, Ma KW, Murota S. Connexin43 suppresses proliferation of osteosarcoma U2OS cells through post-transcriptional regulation of p27. Oncogene. 2001;20:4138-49.

24. Zhang YW, Kaneda M, Morita I. The gap junction-independent tumor-suppressing effect of connexin 43. J Biol Chem. 2003;278:44852-6.

25. Zhu D, Kidder GM, Caveney S, Naus CC. Growth retardation in glioma cells cocultured with cells overexpressing a gap junction protein. Proc Natl Acad Sci USA. 1992;89:10218-21.

26. Hellmann P, Grummer R, Schirrmacher K, Rook M, Traub O, Winterhager E. Transfection with different connexin genes alters growth and differentiation of human choriocarcinoma cells. Exp Cell Res. 1999;246:480-90.

27. Hirschi KK, Xu CE, Tsukamoto T, Sager R. Gap junction genes Cx26 and Cx43 individually suppress the cancer phenotype of human mammary carcinoma cells and restore differentiation potential. Cell growth \& differentiation: the molecular biology journal of the American Association for. Cancer Res. 1996;7:861-70.

28. McLachlan E, Shao Q, Wang HL, Langlois S, Laird DW. Connexins act as tumor suppressors in three-dimensional mammary cell organoids by regulating differentiation and angiogenesis. Cancer Res. 2006;66:9886-94.

29. Shao Q, Wang H, McLachlan E, Veitch GI, Laird DW. Downregulation of $\mathrm{Cx} 43$ by retroviral delivery of small interfering RNA promotes an aggressive breast cancer cell phenotype. Cancer Res. 2005;65:2705-11.

30. Aasen T. Connexins: junctional and non-junctional modulators of proliferation. Cell Tissue Res. 2015;360:685-99.

31. Gilleron J, Carette D, Segretain D, Pointis G. Multiple and complex influences of connexins and pannexins on cell death. Biochim Biophys Acta. 2018;1860:182-91.

32. Kameritsch P, Khandoga N, Pohl U, Pogoda K. Gap junctional communication promotes apoptosis in a connexin-typedependent manner. Cell Death Dis. 2013;4:e584.

33. Krutovskikh VA, Piccoli C, Yamasaki H. Gap junction intercellular communication propagates cell death in cancerous cells. Oncogene. 2002;21:1989-99.

34. Lin Q, Balasubramanian K, Fan D, Kim SJ, Guo L, Wang H, et al. Reactive astrocytes protect melanoma cells from chemotherapy by sequestering intracellular calcium through gap junction communication channels. Neoplasia. 2010;12:748-54.

35. Wang N, De Bock M, Decrock E, Bol M, Gadicherla A, Vinken $\mathrm{M}$, et al. Paracrine signaling through plasma membrane hemichannels. Biochim Biophys Acta. 2013;1828:35-50.

36. Krutovskikh VA, Troyanovsky SM, Piccoli C, Tsuda H, Asamoto M, Yamasaki H. Differential effect of subcellular localization of communication impairing gap junction protein connexin43 on tumor cell growth in vivo. Oncogene. 2000;19:505-13.

37. Olbina G, Eckhart W. Mutations in the second extracellular region of connexin 43 prevent localization to the plasma membrane, but do not affect its ability to suppress cell growth. Mol Cancer Res. 2003;1:690-700.

38. Sirnes S, Bruun J, Kolberg M, Kjenseth A, Lind GE, Svindland A, et al. Connexin 43 acts as a colorectal cancer tumor suppressor and predicts disease outcome. Int J Cancer. 2012;131:570-81.

39. Zhang YW, Nakayama K, Nakayama K, Morita I. A novel route for connexin 43 to inhibit cell proliferation: negative regulation of S-phase kinase-associated protein (Skp 2). Cancer Res. 2003;63:1623-30.
40. Shi Q, Gu S, Yu XS, White TW, Banks EA, Jiang JX. Connexin controls cell-cycle exit and cell differentiation by directly promoting cytosolic localization and degradation of E3 ligase Skp2. Dev Cell. 2015;35:483-96.

41. Duffy HS, Iacobas I, Hotchkiss K, Hirst-Jensen BJ, Bosco A, Dandachi N, et al. The gap junction protein connexin32 interacts with the Src homology 3/hook domain of discs large homolog 1 . J Biol Chem. 2007;282:9789-96.

42. Macdonald AI, Sun P, Hernandez-Lopez H, Aasen T, Hodgins $\mathrm{MB}$, Edward M, et al. A functional interaction between the MAGUK protein $\mathrm{hDlg}$ and the gap junction protein connexin 43 in cervical tumour cells. Biochem J. 2012;446:9-21.

43. Gonzalez-Sanchez A, Jaraiz-Rodriguez M, Dominguez-Prieto M, Herrero-Gonzalez S, Medina JM, Tabernero A. Connexin43 recruits PTEN and Csk to inhibit c-Src activity in glioma cells and astrocytes. Oncotarget. 2016;7:49819-33.

44. Kotini M, Mayor R. Connexins in migration during development and cancer. Dev Biol. 2015;401:143-51.

45. Defamie N, Chepied A. Mesnil M. Connexins, gap junctions and tissue invasion. FEBS Lett. 2014;588:1331-8.

46. el-Sabban ME, Pauli BU. Cytoplasmic dye transfer between metastatic tumor cells and vascular endothelium. J Cell Biol. 1991;115:1375-82.

47. Ito A, Katoh F, Kataoka TR, Okada M, Tsubota N, Asada H, et al. A role for heterologous gap junctions between melanoma and endothelial cells in metastasis. $J$ Clin Invest. 2000;105:1189-97.

48. Pollmann MA, Shao Q, Laird DW, Sandig M. Connexin 43 mediated gap junctional communication enhances breast tumor cell diapedesis in culture. Breast Cancer Res. 2005;7:R522-534.

49. Saito-Katsuragi M, Asada H, Niizeki H, Katoh F, Masuzawa M, Tsutsumi M, et al. Role for connexin 26 in metastasis of human malignant melanoma: communication between melanoma and endothelial cells via connexin 26. Cancer. 2007;110:1162-72.

50. Chen Q, Boire A, Jin X, Valiente M, Er EE, Lopez-Soto A, et al. Carcinoma-astrocyte gap junctions promote brain metastasis by cGAMP transfer. Nature. 2016;533:493-8.

51. Artesi M, Kroonen J, Bredel M, Nguyen-Khac M, Deprez M, Schoysman L, et al. Connexin 30 expression inhibits growth of human malignant gliomas but protects them against radiation therapy. Neuro Oncol. 2015;17:392-406.

52. Munoz JL, Rodriguez-Cruz V, Greco SJ, Ramkissoon SH, Ligon KL, Rameshwar P. Temozolomide resistance in glioblastoma cells occurs partly through epidermal growth factor receptormediated induction of connexin 43. Cell Death Dis. 2014;5: e1145.

53. Osswald M, Jung E, Sahm F, Solecki G, Venkataramani V, Blaes $\mathrm{J}$, et al. Brain tumour cells interconnect to a functional and resistant network. Nature. 2015;528:93-98.

54. Yu SC, Xiao HL, Jiang XF, Wang QL, Li Y, Yang XJ, et al. Connexin 43 reverses malignant phenotypes of glioma stem cells by modulating E-cadherin. Stem Cells. 2012;30:108-20.

55. Gangoso E, Thirant C, Chneiweiss H, Medina JM, Tabernero A. A cell-penetrating peptide based on the interaction between c-Src and connexin 43 reverses glioma stem cell phenotype. Cell Death Dis. 2014;5:e1023.

56. Hitomi M, Deleyrolle LP, Mulkearns-Hubert EE, Jarrar A, Li M, Sinyuk M, et al. Differential connexin function enhances selfrenewal in glioblastoma. Cell Rep. 2015;11:1031-42.

57. Shen Y, Li Y, Ma X, Wan Q, Jiang Z, Liu Y, et al. Connexin 43 SUMOylation improves gap junction functions between liver cancer stem cells and enhances their sensitivity to HSVtk/GCV. Int J Oncol. 2018;52:872-80.

58. Kawasaki Y, Omori Y, Li Q, Nishikawa Y, Yoshioka T, Yoshida $\mathrm{M}$, et al. Cytoplasmic accumulation of connexin32 expands 
cancer stem cell population in human $\mathrm{HuH7}$ hepatoma cells by enhancing its self-renewal. Int J Cancer. 2011;128:51-62.

59. Park SY, Lee HE, Li H, Shipitsin M, Gelman R, Polyak K. Heterogeneity for stem cell-related markers according to tumor subtype and histologic stage in breast cancer. Clin Cancer Res. 2010;16:876-87.

60. Shipitsin M, Campbell LL, Argani P, Weremowicz S, Bloushtain-Qimron N, Yao J, et al. Molecular definition of breast tumor heterogeneity. Cancer Cell. 2007;11:259-73.

61. Busby M, Hallett MT, Plante I. The complex subtype-dependent role of connexin 43 (GJA1) in breast cancer. Int J Mol Sci. 2018;19:693.

62. Thiagarajan PS, Sinyuk M, Turaga SM, Mulkearns-Hubert EE, Hale JS, Rao V, et al. Cx26 drives self-renewal in triple-negative breast cancer via interaction with NANOG and focal adhesion kinase. Nat Commun. 2018;9:578.

63. Uhlen M, Zhang C, Lee S, Sjostedt E, Fagerberg L, Bidkhori G et al. A pathology atlas of the human cancer transcriptome. Science. 2017;357:pii: eaan2507.

64. Teleki I, Szasz AM, Maros ME, Gyorffy B, Kulka J, Meggyeshazi $\mathrm{N}$, et al. Correlations of differentially expressed gap junction connexins Cx26, Cx30, Cx32, Cx43 and Cx46 with breast cancer progression and prognosis. PLoS One. 2014;9: e112541.

65. Murphy SF, Varghese RT, Lamouille S, Guo S, Pridham KJ, Kanabur P, et al. Connexin 43 inhibition sensitizes chemoresistant glioblastoma cells to temozolomide. Cancer Res. 2016;76:139-49.

66. Haass NK, Ripperger D, Wladykowski E, Dawson P, Gimotty $\mathrm{PA}$, Blome $\mathrm{C}$, et al. Melanoma progression exhibits a significant impact on connexin expression patterns in the epidermal tumor microenvironment. Histochem Cell Biol. 2010;133:113-24.

67. Lin YP, Wu JI, Tseng CW, Chen HJ, Wang LH. Gjb4 serves as a novel biomarker for lung cancer and promotes metastasis and chemoresistance via Src activation. Oncogene. 2018;38:822-37.

68. Zhu T, Gao YF, Chen YX, Wang ZB, Yin JY, Mao XY, et al. Genome-scale analysis identifies GJB2 and ERO1LB as prognosis markers in patients with pancreatic cancer. Oncotarget. 2017;8:21281-9.

69. Castellana B, Escuin D, Peiro G, Garcia-Valdecasas B, Vazquez $\mathrm{T}$, Pons $\mathrm{C}$, et al. ASPN and GJB2 are implicated in the mechanisms of invasion of ductal breast carcinomas. J Cancer. 2012;3:175-83.

70. Dubina MV, Iatckii NA, Popov DE, Vasil'ev SV, Krutovskikh VA. Connexin 43 , but not connexin 32 , is mutated at advanced stages of human sporadic colon cancer. Oncogene. 2002;21:4992-6.

71. Jing YM, Guo SX, Zhang XP, Sun AJ, Tao F, Qian HX. Association between C1019T polymorphism in the connexin 37 gene and Helicobacter pylori infection in patients with gastric cancer. Asian Pac J Cancer Prev. 2012;13:2363-7.

72. Naoi Y, Miyoshi Y, Taguchi T, Kim SJ, Arai T, Maruyama N, et al. Connexin26 expression is associated with aggressive phenotype in human papillary and follicular thyroid cancers. Cancer Lett. 2008;262:248-56.

73. Harris LD, De La Cerda J, Tuziak T, Rosen D, Xiao L, Shen Y, et al. Analysis of the expression of biomarkers in urinary bladder cancer using a tissue microarray. Mol Carcinogen. 2008;47:678-85.

74. Sentani K, Oue N, Sakamoto N, Anami K, Naito Y, Aoyagi K, et al. Upregulation of connexin 30 in intestinal phenotype gastric cancer and its reduction during tumor progression. Pathobiology. 2010;77:241-8.

75. Tang B, Peng ZH, Yu PW, Yu G, Qian F, Zeng DZ, et al. Aberrant expression of $\mathrm{Cx} 43$ is associated with the peritoneal metastasis of gastric cancer and Cx43-mediated gap junction enhances gastric cancer cell diapedesis from peritoneal mesothelium. PLoS One. 2013;8:e74527.

76. Kyo N, Yamamoto H, Takeda Y, Ezumi K, Ngan CY, Terayama $\mathrm{M}$, et al. Overexpression of connexin 26 in carcinoma of the pancreas. Oncol Rep. 2008;19:627-31.

77. Ezumi K, Yamamoto H, Murata K, Higashiyama M, Damdinsuren B, Nakamura Y, et al. Aberrant expression of connexin 26 is associated with lung metastasis of colorectal cancer. Clinical cancer research: an official journal of the American Association for. Cancer Res. 2008;14:677-84.

78. Mehta PP, Perez-Stable C, Nadji M, Mian M, Asotra K, Roos BA. Suppression of human prostate cancer cell growth by forced expression of connexin genes. Dev Genet. 1999;24:91-110.

79. Crespin S, Fromont G, Wager M, Levillain P, Cronier L, Monvoisin A, et al. Expression of a gap junction protein, connexin43, in a large panel of human gliomas: new insights. Cancer Med. 2016;5:1742-52.

80. Kotini M, Barriga EH, Leslie J, Gentzel M, Rauschenberger V, Schambon A, et al. Gap junction protein Connexin-43 is a direct transcriptional regulator of $\mathrm{N}$-cadherin in vivo. Nat Commun. 2018;9:3846.

81. Pogoda K, Kameritsch P, Retamal MA, Vega JL. Regulation of gap junction channels and hemichannels by phosphorylation and redox changes: a revision. BMC Cell Biol. 2016;17(Suppl 1):11.

82. King TJ, Bertram JS. Connexins as targets for cancer chemoprevention and chemotherapy. Biochim Biophys Acta. 2005; 1719:146-60.

83. Yu ML, Zhang CL, Yuan DD, Tong XH, Tao L. Panax notoginseng saponins enhances the cytotoxicity of cisplatin via increasing gap junction intercellular communication. Biol Pharm Bull. 2012;35:1230-7.

84. Willebrords J, Maes M, Crespo Yanguas S, Vinken M. Inhibitors of connexin and pannexin channels as potential therapeutics. Pharmacol Ther. 2017;180:144-60.

85. Zibara K, Awada Z, Dib L, El-Saghir J, Al-Ghadban S, Ibrik A, et al. Anti-angiogenesis therapy and gap junction inhibition reduce MDA-MB-231 breast cancer cell invasion and metastasis in vitro and in vivo. Sci Rep. 2015;5:12598.

86. Wang H, Tian L, Liu J, Goldstein A, Bado I, Zhang W, et al. The osteogenic niche is a calcium reservoir of bone micrometastases and confers unexpected therapeutic vulnerability. Cancer Cell. 2018;34:823-39 e827.

87. Alonso F, Domingos-Pereira S, Le Gal L, Derre L, Meda P, Jichlinski $\mathrm{P}$, et al. Targeting endothelial connexin 40 inhibits tumor growth by reducing angiogenesis and improving vessel perfusion. Oncotarget. 2016;7:14015-28.

88. Yusubalieva GM, Baklaushev VP, Gurina OI, Gulyaev MV, Pirogov YA, Chekhonin VP. Antitumor effects of monoclonal antibodies to connexin 43 extracellular fragment in induced lowdifferentiated glioma. Bull Exp Biol Med. 2012;153:163-9.

89. Yusubalieva GM, Baklaushev VP, Gurina OI, Zorkina YA, Gubskii IL, Kobyakov GL, et al. Treatment of poorly differentiated glioma using a combination of monoclonal antibodies to extracellular connexin-43 fragment, temozolomide, and radiotherapy. Bull Exp Biol Med. 2014;157:510-5.

90. Chekhonin VP, Baklaushev VP, Yusubalieva GM, Belorusova AE, Gulyaev MV, Tsitrin EB, et al. Targeted delivery of liposomal nanocontainers to the peritumoral zone of glioma by means of monoclonal antibodies against GFAP and the extracellular loop of $\mathrm{Cx} 43$. Nanomedicine. 2012;8:63-70.

91. Nukolova NV, Baklaushev VP, Abakumova TO, Mel'nikov PA, Abakumov MA, Yusubalieva GM, et al. Targeted delivery of cisplatin by small es, Cyrilliconnexin 43 vector nanogels to the focus of experimental glioma C6. Bull Exp Biol Med. 2014;157:524-9. 
92. Bennett MV, Contreras JE, Bukauskas FF, Saez JC. New roles for astrocytes: gap junction hemichannels have something to communicate. Trends Neurosci. 2003;26:610-7.

93. Chi Y, Gao K, Li K, Nakajima S, Kira S, Takeda M, et al. Purinergic control of AMPK activation by ATP released through connexin 43 hemichannels - pivotal roles in hemichannelmediated cell injury. J Cell Sci. 2014;127:1487-99.

94. Riquelme MA, Kar R, Gu S, Jiang JX. Antibodies targeting extracellular domain of connexins for studies of hemichannels. Neuropharmacology. 2013;75:525-32.

95. Zhou JZ, Riquelme MA, Gu S, Kar R, Gao X, Sun L, et al. Osteocytic connexin hemichannels suppress breast cancer growth and bone metastasis. Oncogene. 2016;35:5597-607.

96. Zhou JZ, Riquelme MA, Gao X, Ellies LG, Sun LZ, Jiang JX. Differential impact of adenosine nucleotides released by osteocytes on breast cancer growth and bone metastasis. Oncogene. 2015;34:1831-42.

97. Leithe E, Mesnil M, Aasen T. The connexin 43 C-terminus: a tail of many tales. Biochim Biophys Acta. 2018;1860:48-64.

98. Tabernero A, Gangoso E, Jaraiz-Rodriguez M, Medina JM. The role of connexin43-Src interaction in astrocytomas: A molecular puzzle. Neuroscience. 2016;323:183-94.

99. Herrero-Gonzalez S, Gangoso E, Giaume C, Naus CC, Medina JM, Tabernero A. Connexin43 inhibits the oncogenic activity of c-Src in C6 glioma cells. Oncogene. 2010;29:5712-23.

100. Jaraiz-Rodriguez M, Tabernero MD, Gonzalez-Tablas M, Otero A, Orfao A, Medina JM, et al. A short region of connexin43 reduces human glioma stem cell migration, invasion, and survival through Src, PTEN, and FAK. Stem Cell Rep. 2017;9:45163.

101. Kameritsch P, Kiemer F, Beck H, Pohl U, Pogoda K. Cx43 increases serum induced filopodia formation via activation of p21-activated protein kinase 1. Biochim Biophys Acta. 2015;1853:2907-17.

102. Dai P, Nakagami T, Tanaka H, Hitomi T, Takamatsu T. Cx43 mediates TGF-beta signaling through competitive Smads binding to microtubules. Mol Biol Cell. 2007;18:2264-73.

103. Hunter AW, Barker RJ, Zhu C, Gourdie RG. Zonula occludens-1 alters connexin 43 gap junction size and organization by influencing channel accretion. Mol Biol Cell. 2005;16:5686-98.

104. Rhett JM, Jourdan J, Gourdie RG. Connexin 43 connexon to gap junction transition is regulated by zonula occludens-1. Mol Biol Cell. 2011;22:1516-28.

105. Grek CL, Rhett JM, Bruce JS, Abt MA, Ghatnekar GS, Yeh ES. Targeting connexin 43 with alpha-connexin carboxyl-terminal (ACT1) peptide enhances the activity of the targeted inhibitors, tamoxifen and lapatinib, in breast cancer: clinical implication for ACT1. BMC Cancer. 2015;15:296.

106. Naus CC, Giaume C. Bridging the gap to therapeutic strategies based on connexin/pannexin biology. J Transl Med. 2016;14:330.

107. Seymour CB, Mothersill C. Radiation-induced bystander effects -implications for cancer. Nat Rev Cancer. 2004;4:158.

108. Greco R, Oliveira G, Stanghellini MTL, Vago L, Bondanza A, Peccatori J. Improving the safety of cell therapy with the TKsuicide gene. Front Pharmacol. 2015;6:95.

109. Elshami AA, Saavedra A, Zhang H, Kucharczuk JC, Spray DC, Fishman GI, et al. Gap junctions play a role in the 'bystander effect' of the herpes simplex virus thymidine kinase/ganciclovir system in vitro. Gene Ther. 1996;3:85-92.

110. Fick J, Barker FG 2nd, Dazin P, Westphale EM, Beyer EC, Israel MA. The extent of heterocellular communication mediated by gap junctions is predictive of bystander tumor cytotoxicity in vitro. Proc Natl Acad Sci USA. 1995;92:11071-5.

111. Pitts JD. Cancer gene therapy: a bystander effect using the gap junctional pathway. Mol Carcinog. 1994;11:127-30.
112. Mesnil M, Piccoli C, Tiraby G, Willecke K, Yamasaki H. Bystander killing of cancer cells by herpes simplex virus thymidine kinase gene is mediated by connexins. Proc Natl Acad Sci USA. 1996;93:1831-5.

113. Dilber MS, Abedi MR, Christensson B, Bjorkstrand B, Kidder GM, Naus CC, et al. Gap junctions promote the bystander effect of herpes simplex virus thymidine kinase in vivo. Cancer Res. 1997;57:1523-8.

114. Vrionis FD, Wu JK, Qi P, Waltzman M, Cherington V, Spray DC. The bystander effect exerted by tumor cells expressing the herpes simplex virus thymidine kinase (HSVtk) gene is dependent on connexin expression and cell communication via gap junctions. Gene Ther. 1997;4:577-85.

115. Touraine RL, Ishii-Morita H, Ramsey WJ, Blaese RM. The bystander effect in the HSVtk/ganciclovir system and its relationship to gap junctional communication. Gene Ther. 1998;5:1705-11.

116. Duflot-Dancer A, Piccoli C, Rolland A, Yamasaki H, Mesnil M. Long-term connexin-mediated bystander effect in highly tumorigenic human cells in vivo in herpes simplex virus thymidine kinase/ganciclovir gene therapy. Gene Ther. 1998;5:1372-8.

117. Mesnil M, Yamasaki H. Bystander effect in herpes simplex virus-thymidine kinase/ganciclovir cancer gene therapy: role of gap-junctional intercellular communication. Cancer Res. 2000;60:3989-99.

118. Kong H, Liu X, Yang L, Qi K, Zhang H, Zhang J, et al. All-trans retinoic acid enhances bystander effect of suicide gene therapy in the treatment of breast cancer. Oncol Rep. 2016;35:1868-74.

119. Dahle J, Mikalsen S, Rivedal E, Steen H. Gap junction intercellular communication is not a major mediator in the bystander effect in photodynamic treatment of MDCKII cells. Radiat Res. 2000;154:10.

120. Prise KM, O'Sullivan JM. Radiation-induced bystander signalling in cancer therapy. Nat Rev Cancer. 2009;9:351.

121. Wygoda MR, Wilson MR, Davis MA, Trosko JE, Rehemtulla A, Lawrence TS. Protection of herpes simplex virus thymidine kinase-transduced cells from ganciclovir-mediated cytotoxicity by bystander cells: the Good Samaritan effect. Cancer Res. 1997;57:1699-703.

122. Saez CG, Velasquez L, Montoya M, Eugenin E, Alvarez MG. Increased gap junctional intercellular communication is directly related to the anti-tumor effect of all-trans-retinoic acid plus tamoxifen in a human mammary cancer cell line. J Cell Biochem. 2003;89:450-61.

123. Carystinos GD, Alaoui-Jamali MA, Phipps J, Yen L, Batist G. Upregulation of gap junctional intercellular communication and connexin 43 expression by cyclic-AMP and all-trans-retinoic acid is associated with glutathione depletion and chemosensitivity in neuroblastoma cells. Cancer Chemother Pharmacol. 2001;47:126-32.

124. Wang Y, Zhang C, Zhang S, Zhao Z, Wang J, Song J, et al. Kanglaite sensitizes colorectal cancer cells to Taxol via NFkappaBeta inhibition and connexin 43 upregulation. Sci Rep. 2017;7:1280.

125. Wu JF, Ji J, Dong SY, Li BB, Yu ML, Wu DD, et al. Gefitinib enhances oxaliplatin-induced apoptosis mediated by $\mathrm{Src}$ and PKC-modulated gap junction function. Oncol Rep. 2016;36:3251-8.

126. Wang L, Fu Y, Peng J, Wu D, Yu M, Xu C, et al. Simvastatininduced up-regulation of gap junctions composed of connexin 43 sensitize Leydig tumor cells to etoposide: an involvement of PKC pathway. Toxicology. 2013;312:149-57.

127. Wang L, Peng J, Huang H, Wang Q, Yu M, Tao L. Simvastatin protects Sertoli cells against cisplatin cytotoxicity through enhanced gap junction intercellular communication. Oncol Rep. 2015;34:2133-41. 
128. Liu D, Zhou H, Wu J, Liu W, Li Y, Shi G, et al. Infection by Cx43 adenovirus increased chemotherapy sensitivity in human gastric cancer BGC-823 cells: not involving in induction of cell apoptosis. Gene. 2015;574:217-24.

129. Huang RP, Hossain MZ, Huang R, Gano J, Fan Y, Boynton AL. Connexin 43 (cx43) enhances chemotherapy-induced apoptosis in human glioblastoma cells. Int J Cancer. 2001;92:130-8.

130. Raza A, Ghoshal A, Chockalingam S, Ghosh SS. Connexin-43 enhances tumor suppressing activity of artesunate via gap junction-dependent as well as independent pathways in human breast cancer cells. Sci Rep. 2017;7:7580.

131. Sato H, Senba H, Virgona N, Fukumoto K, Ishida T, Hagiwara H, et al. Connexin 32 potentiates vinblastine-induced cytotoxicity in renal cell carcinoma cells. Mol Carcinog. 2007;46:215-24.

132. Tanaka M, Grossman HB. Connexin 26 gene therapy of human bladder cancer: induction of growth suppression, apoptosis, and synergy with Cisplatin. Hum Gene Ther. 2001;12:2225-36.

133. Tanaka M, Grossman HB. Connexin 26 induces growth suppression, apoptosis and increased efficacy of doxorubicin in prostate cancer cells. Oncol Rep. 2004;11:537-41.

134. Chen W, Wang D, Du X, He Y, Chen S, Shao Q, et al. Glioma cells escaped from cytotoxicity of temozolomide and vincristine by communicating with human astrocytes. Med Oncol. 2015;32:43.

135. Gielen PR, Aftab Q, Ma N, Chen VC, Hong X, Lozinsky S, et al. Connexin 43 confers Temozolomide resistance in human glioma cells by modulating the mitochondrial apoptosis pathway. Neuropharmacology. 2013;75:539-48.

136. Yulyana Y, Endaya BB, Ng WH, Guo CM, Hui KM, Lam PY, et al. Carbenoxolone enhances TRAIL-induced apoptosis through the upregulation of death receptor 5 and inhibition of gap junction intercellular communication in human glioma. Stem Cells Dev. 2013;22:1870-82.

137. Yang J, Qin G, Luo M, Chen J, Zhang Q, Li L, et al. Reciprocal positive regulation between $\mathrm{Cx} 26$ and PI3K/Akt pathway confers acquired gefitinib resistance in NSCLC cells via GJICindependent induction of EMT. Cell Death Dis. 2015;6:e1829.

138. Mulkearns-Hubert EE, Torre-Healy LA, Silver DJ, Eurich JT, Serbinowski E, Hitomi M et al. Development of a Cx46 targeting strategy for cancer stem cells. bioRxivorg. 2018.

139. Falk S. Carbenoxolone as a novel therapy for attenuation of cancer-induced bone pain. Pain. 2018;159:1127-36.

140. Mehta PP, Bertram JS, Loewenstein WR. Growth inhibition of transformed cells correlates with their junctional communication with normal cells. Cell. 1986;44:187-96.

141. Gleisner MA, Navarrete M, Hofmann F, Salazar-Onfray F, Tittarelli A. Mind the gaps in tumor immunity: impact of connexinmediated intercellular connections. Front Immunol. 2017;8:1067.

142. Mendoza-Naranjo A, Saez PJ, Johansson CC, Ramirez M, Mandakovic D, Pereda C, et al. Functional gap junctions facilitate melanoma antigen transfer and cross-presentation between human dendritic cells. J Immunol. 2007;178:6949-57.

143. Saccheri F, Pozzi C, Avogadri F, Barozzi S, Faretta M, Fusi P, et al. Bacteria-induced gap junctions in tumors favor antigen cross-presentation and antitumor immunity. Sci Transl Med. 2010;2:44ra57.

144. Tittarelli A, Janji B, Van Moer K, Noman MZ, Chouaib S. The selective degradation of synaptic connexin 43 protein by hypoxia-induced autophagy impairs natural killer cell-mediated tumor cell killing. J Biol Chem. 2015;290:23670-9.

145. Tittarelli A, Mendoza-Naranjo A, Farias M, Guerrero I, Ihara F, Wennerberg E, et al. Gap junction intercellular communications regulate NK cell activation and modulate NK cytotoxic capacity. J Immunol. 2014;192:1313-9.

146. Aucher A, Rudnicka D, Davis DM. MicroRNAs transfer from human macrophages to hepato-carcinoma cells and inhibit proliferation. J Immunol. 2013;191:6250-60.
147. Glass AM, Snyder EG, Taffet SM. Connexins and pannexins in the immune system and lymphatic organs. Cell Mol Life Sci. 2015;72:2899-910.

148. Potente M, Gerhardt H, Carmeliet P. Basic and therapeutic aspects of angiogenesis. Cell. 2011;146:873-87.

149. Wang WK, Chen MC, Leong HF, Kuo YL, Kuo CY, Lee CH. Connexin 43 suppresses tumor angiogenesis by down-regulation of vascular endothelial growth factor via hypoxic-induced factor1alpha. Int J Mol Sci. 2014;16:439-51.

150. Gartner C, Ziegelhoffer B, Kostelka M, Stepan H, Mohr FW, Dhein S. Knock-down of endothelial connexins impairs angiogenesis. Pharmacol Res. 2012;65:347-57.

151. Haefliger JA, Allagnat F, Hamard L, Le Gal L, Meda P, NardelliHaefliger D, et al. Targeting $\mathrm{Cx} 40$ (Connexin40) expression or function reduces angiogenesis in the developing mouse retina. Arterioscler Thromb Vasc Biol. 2017;37:2136-46.

152. de Wit C, Wolfle SE, Hopfl B. Connexin-dependent communication within the vascular wall: contribution to the control of arteriolar diameter. Adv Cardiol. 2006;42:268-83.

153. Segal SS. Integration and modulation of intercellular signaling underlying blood flow control. J Vasc Res. 2015;52:136-57.

154. Thuringer D, Jego G, Berthenet K, Hammann A, Solary E, Garrido C. Gap junction-mediated transfer of miR-145-5p from microvascular endothelial cells to colon cancer cells inhibits angiogenesis. Oncotarget. 2016;7:28160-8.

155. Thuringer D, Boucher J, Jego G, Pernet N, Cronier L, Hammann A, et al. Transfer of functional microRNAs between glioblastoma and microvascular endothelial cells through gap junctions. Oncotarget. 2016;7:73925-34.

156. Elzarrad MK, Haroon A, Willecke K, Dobrowolski R, Gillespie $\mathrm{MN}$, Al-Mehdi AB. Connexin-43 upregulation in micrometastases and tumor vasculature and its role in tumor cell attachment to pulmonary endothelium. BMC Med. 2008;6:20.

157. Villares GJ, Dobroff AS, Wang H, Zigler M, Melnikova VO, Huang L, et al. Overexpression of protease-activated receptor-1 contributes to melanoma metastasis via regulation of connexin 43. Cancer Res. 2009;69:6730-7.

158. Stoletov K, Strnadel J, Zardouzian E, Momiyama M, Park FD, Kelber JA, et al. Role of connexins in metastatic breast cancer and melanoma brain colonization. J Cell Sci. 2013;126:904-13.

159. Thuringer D, Berthenet K, Cronier L, Solary E, Garrido C. Primary tumor- and metastasis-derived colon cancer cells differently modulate connexin expression and function in human capillary endothelial cells. Oncotarget. 2015;6:28800-15.

160. Karpinich NO, Caron KM. Gap junction coupling is required for tumor cell migration through lymphatic endothelium. Arterioscler Thromb Vasc Biol. 2015;35:1147-55.

161. Lin JH, Takano T, Cotrina ML, Arcuino G, Kang J, Liu S, et al. Connexin 43 enhances the adhesivity and mediates the invasion of malignant glioma cells. J Neurosci. 2002;22:4302-11.

162. Sin WC, Aftab Q, Bechberger JF, Leung JH, Chen H, Naus CC. Astrocytes promote glioma invasion via the gap junction protein connexin43. Oncogene. 2016;35:1504-16.

163. Oliveira R, Christov C, Guillamo JS, de Bouard S, Palfi S, Venance $\mathrm{L}$, et al. Contribution of gap junctional communication between tumor cells and astroglia to the invasion of the brain parenchyma by human glioblastomas. BMC Cell Biol. 2005;6:7.

164. Hong X, Sin WC, Harris AL, Naus CC. Gap junctions modulate glioma invasion by direct transfer of microRNA. Oncotarget. 2015;6:15566-77.

165. Lin Q, Liu Z, Ling F, Xu G. Astrocytes protect glioma cells from chemotherapy and upregulate survival genes via gap junctional communication. Mol Med Rep. 2016;13:1329-35.

166. Lai SW, Huang BR, Liu YS, Lin HY, Chen CC, Tsai CF. et al. Differential characterization of temozolomide-resistant human glioma cells. Int J Mol Sci. 2018;19:127. 
167. Menachem A, Makovski V, Bodner O, Pasmanik-Chor M, Stein $\mathrm{R}$, Shomron $\mathrm{N}$, et al. Intercellular transfer of small RNAs from astrocytes to lung tumor cells induces resistance to chemotherapy. Oncotarget. 2016;7:12489-504.

168. de Martel C, Plummer M, Vignat J, Franceschi S. Worldwide burden of cancer attributable to HPV by site, country and HPV type. Int J Cancer. 2017;141:664-70.

169. Khoo NK, Zhang Y, Bechberger JF, Bond SL, Hum K, Lala PK. SV40 Tag transformation of the normal invasive trophoblast results in a premalignant phenotype. II. Changes in gap junctional intercellular communication. Int J Cancer. 1998;77:440-8.

170. Khan Z, Yaiw KC, Wilhelmi V, Lam H, Rahbar A, Stragliotto G, et al. Human cytomegalovirus immediate early proteins promote degradation of connexin 43 and disrupt gap junction communication: implications for a role in gliomagenesis. Carcinogenesis. 2014;35:145-54.

171. McNutt NS, Weinstein RS. Carcinoma of the cervix: deficiency of nexus intercellular junctions. Science. 1969;165:597-9.

172. zur Hausen H. Papillomaviruses in the causation of human cancers - a brief historical account. Virology. 2009;384:260-5.

173. Aasen T, Graham SV, Edward M, Hodgins MB. Reduced expression of multiple gap junction proteins is a feature of cervical dysplasia. Mol Cancer. 2005;4:31.

174. Aasen T, Hodgins MB, Edward M, Graham SV. The relationship between connexins, gap junctions, tissue architecture and tumour invasion, as studied in a novel in vitro model of HPV-16associated cervical cancer progression. Oncogene. 2003;22:7969-80.

175. Klymenko T, Gu Q, Herbert I, Stevenson A, Iliev V, Watkins G. et al. RNASeq analysis of differentiated keratinocytes reveals a massive response to late events during human papillomavirus type 16 infection, including loss of epithelial barrier function. J Virol. 2017;91:e01001-17.

176. Sun P, Dong L, MacDonald AI, Akbari S, Edward M, Hodgins MB, et al. HPV16 E6 controls the gap junction protein Cx43 in cervical tumour cells. Viruses. 2015;7:5243-56.

177. Oelze I, Kartenbeck J, Crusius K, Alonso A. Human papillomvirus type $16 \mathrm{E} 5$ protein affects cell-cell communication in an epithelial cell line. J Virol. 1995;69:4489-94.

178. Ablasser A, Schmid-Burgk JL, Hemmerling I, Horvath GL, Schmidt T, Latz E, et al. Cell intrinsic immunity spreads to bystander cells via the intercellular transfer of cGAMP. Nature. 2013;503:530-4.

179. Ariazi J, Benowitz A, De Biasi V, Den Boer ML, Cherqui S, Cui $\mathrm{H}$, et al. Tunneling nanotubes and gap junctions-their role in long-range intercellular communication during development, health, and disease conditions. Front Mol Neurosci. 2017;10:333.

180. Wang X, Veruki ML, Bukoreshtliev NV, Hartveit E, Gerdes HH. Animal cells connected by nanotubes can be electrically coupled through interposed gap-junction channels. Proc Natl Acad Sci USA. 2010;107:17194-9.

181. Pasquier J, Guerrouahen BS, Al Thawadi H, Ghiabi P, Maleki $\mathrm{M}$, Abu-Kaoud N, et al. Preferential transfer of mitochondria from endothelial to cancer cells through tunneling nanotubes modulates chemoresistance. J Transl Med. 2013;11:94.

182. Polak R, de Rooij B, Pieters R, den Boer ML. B-cell precursor acute lymphoblastic leukemia cells use tunneling nanotubes to orchestrate their microenvironment. Blood. 2015;126:2404-14.

183. Thayanithy V, Dickson EL, Steer C, Subramanian S, Lou E. Tumor-stromal cross talk: direct cell-to-cell transfer of oncogenic microRNAs via tunneling nanotubes. Transl Res. 2014;164:35965.

184. Osswald M, Solecki G, Wick W, Winkler F. A malignant cellular network in gliomas: potential clinical implications. Neuro Oncol. 2016;18:479-85.
185. Melo SA, Sugimoto H, O'Connell JT, Kato N, Villanueva A, Vidal A, et al. Cancer exosomes perform cell-independent microRNA biogenesis and promote tumorigenesis. Cancer Cell. 2014;26:707-21.

186. Soares AR, Martins-Marques T, Ribeiro-Rodrigues T, Ferreira JV, Catarino S, Pinho MJ, et al. Gap junctional protein Cx43 is involved in the communication between extracellular vesicles and mammalian cells. Sci Rep. 2015;5:13243.

187. Lazar I, Clement E, Ducoux-Petit M, Denat L, Soldan V, Dauvillier $\mathrm{S}$, et al. Proteome characterization of melanoma exosomes reveals a specific signature for metastatic cell lines. Pigment Cell Melanoma Res. 2015;28:464-75.

188. Martins-Marques T, Pinho MJ, Zuzarte M, Oliveira C, Pereira P, Sluijter JP, et al. Presence of $\mathrm{Cx} 43$ in extracellular vesicles reduces the cardiotoxicity of the anti-tumour therapeutic approach with doxorubicin. J Extracell Vesicles. 2016;5:32538.

189. Soung YH, Ford S, Zhang V, Chung J. Exosomes in cancer diagnostics. Cancers. 2017;9:8.

190. Poyet C, Buser L, Roudnicky F, Detmar M, Hermanns T, Mannhard D, et al. Connexin 43 expression predicts poor progression-free survival in patients with non-muscle invasive urothelial bladder cancer. J Clin Pathol. 2015;68:819-24.

191. Balla P, Maros ME, Barna G, Antal I, Papp G, Sapi Z, et al. Prognostic impact of reduced connexin43 expression and gap junction coupling of neoplastic stromal cells in giant cell tumor of bone. PLoS One. 2015;10:e0125316.

192. Naoi Y, Miyoshi Y, Taguchi T, Kim SJ, Arai T, Tamaki Y, et al. Connexin26 expression is associated with lymphatic vessel invasion and poor prognosis in human breast cancer. Breast Cancer Res Treat. 2007;106:11-17.

193. Teleki I, Krenacs T, Szasz MA, Kulka J, Wichmann B, Leo C, et al. The potential prognostic value of connexin 26 and 46 expression in neoadjuvant-treated breast cancer. BMC Cancer. 2013;13:50

194. Chasampalioti M, Green AR, Ellis IO, Rakha EA, Jackson AM, Spendlove I et al. Connexin 43 is an independent predictor of patient outcome in breast cancer patients. Breast Cancer Res Treat. 2018.

195. Nomura S, Maeda K, Noda E, Inoue T, Fukunaga S, Nagahara $\mathrm{H}$, et al. Clinical significance of the expression of connexin26 in colorectal cancer. J Exp Clin Cancer Res. 2010;29:79.

196. Knosel T, Emde A, Schluns K, Chen Y, Jurchott K, Krause M, et al. Immunoprofiles of 11 biomarkers using tissue microarrays identify prognostic subgroups in colorectal cancer. Neoplasia. 2005;7:741-7.

197. Inose T, Kato H, Kimura H, Faried A, Tanaka N, Sakai M, et al. Correlation between connexin 26 expression and poor prognosis of esophageal squamous cell carcinoma. Ann Surg Oncol. 2009;16:1704-10.

198. Tanaka T, Kimura M, Ishiguro H, Mizoguchi K, Takeyama H. Connexin 43 expression is associated with poor survival in patients with esophageal squamous cell carcinoma. Mol Clin Oncol. 2016;4:989-93

199. Liu X, Furuya T, Li D, Xu J, Cao X, Li Q, et al. Connexin 26 expression correlates with less aggressive phenotype of intestinal type-gastric carcinomas. Int J Mol Med. 2010;25:709-16.

200. Danos K, Brauswetter D, Birtalan E, Pato A, Bencsik G, Krenacs $\mathrm{T}$, et al. The potential prognostic value of connexin 43 expression in head and neck squamous cell carcinomas. Appl Immunohistochem Mol Morphol. 2016;24:476-81.

201. Wang ZS, Wu LQ, Yi X, Geng C, Li YJ, Yao RY. Connexin-43 can delay early recurrence and metastasis in patients with hepatitis B-related hepatocellular carcinoma and low serum alphafetoprotein after radical hepatectomy. BMC Cancer. 2013;13:306.

202. Ito A, Koma Y, Uchino K, Okada T, Ohbayashi C, Tsubota N, et al. Increased expression of connexin 26 in the invasive 
component of lung squamous cell carcinoma: significant correlation with poor prognosis. Cancer Lett. 2006;234:239-48.

203. Du G, Yang Y, Zhang Y, Sun T, Liu W, Wang Y, et al. Thrombocytosis and immunohistochemical expression of connexin 43 at diagnosis predict survival in advanced non-small-cell lung cancer treated with cisplatin-based chemotherapy. Cancer Chemother Pharmacol. 2013;71:893-904.

204. Brockmeyer P, Jung K, Perske C, Schliephake H, Hemmerlein B. Membrane connexin 43 acts as an independent prognostic marker in oral squamous cell carcinoma. Int $\mathrm{J}$ Oncol. 2014;45:273-81.

205. Liang QL, Wang BR, Chen GQ, Li GH, Xu YY. Clinical significance of vascular endothelial growth factor and connexin 43 for predicting pancreatic cancer clinicopathologic parameters. Med Oncol. 2010;27:1164-70.

206. Bijnsdorp IV, Rozendaal L, van Moorselaar RJ, Geldof AA. A predictive role for noncancerous prostate cells: low connexin-26 expression in radical prostatectomy tissues predicts metastasis. Br J Cancer. 2012;107:1963-8.

207. Benko G, Spajic B, Demirovic A, Stimac G, Kru Sbreve Lin B, Tomas D. Prognostic value of connexin43 expression in patients with clinically localized prostate cancer. Prostate Cancer Prostatic Dis. 2011;14:90-95.

208. Xu N, Chen HJ, Chen SH, Xue XY, Chen H, Zheng QS, et al. Reduced Connexin 43 expression is associated with tumor malignant behaviors and biochemical recurrence-free survival of prostate cancer. Oncotarget. 2016;7:67476-84.

209. Bui MM, Han G, Acs G, Reed D, Gonzalez RJ, Pasha TL, et al. Connexin 43 is a potential prognostic biomarker for ewing sarcoma/primitive neuroectodermal tumor. Sarcoma. 2011;2011:971050.

210. Buhrmann C, Shayan P, Kraehe P, Popper B, Goel A, Shakibaei M. Resveratrol induces chemosensitization to 5-fluorouracil through up-regulation of intercellular junctions, epithelial-tomesenchymal transition and apoptosis in colorectal cancer. Biochem Pharmacol. 2015;98:51-68.

211. Harikumar KB, Kunnumakkara AB, Sethi G, Diagaradjane P, Anand P, Pandey MK, et al. Resveratrol, a multitargeted agent, can enhance antitumor activity of gemcitabine in vitro and in orthotopic mouse model of human pancreatic cancer. Int $\mathbf{J}$ Cancer. 2010;127:257-68.
212. Fukushima M, Hattori Y, Yoshizawa T, Maitani Y. Combination of non-viral connexin 43 gene therapy and docetaxel inhibits the growth of human prostate cancer in mice. Int $\mathrm{J}$ Oncol. 2007;30:225-31.

213. Shishido SN, Delahaye A, Beck A, Nguyen TA. The anticancer effect of PQ1 in the MMTV-PyVT mouse model. Int J Cancer. 2014;134:1474-83.

214. Shishido SN, Nguyen TA. Gap junction enhancer increases efficacy of cisplatin to attenuate mammary tumor growth. PLoS One. 2012;7:e44963.

215. Li S, Gao Y, Pu K, Ma L, Song X, Liu Y. All-trans retinoic acid enhances bystander effect of suicide-gene therapy against medulloblastomas. Neurosci Lett. 2011;503:115-9.

216. Wu L, Zhou WB, Shen F, Liu W, Wu HW, Zhou SJ, et al. Connexin32mediated antitumor effects of suicide gene therapy against hepatocellular carcinoma: In vitro and in vivo anticancer activity. Mol Med Rep. 2016;13:3213-9.

217. Ryu CH, Park KY, Kim SM, Jeong CH, Woo JS, Hou Y, et al. Valproic acid enhances anti-tumor effect of mesenchymal stem cell mediated HSV-TK gene therapy in intracranial glioma. Biochem Biophys Res Commun. 2012;421:585-90.

218. Touraine RL, Vahanian N, Ramsey WJ, Blaese RM. Enhancement of the herpes simplex virus thymidine kinase/ganciclovir bystander effect and its antitumor efficacy in vivo by pharmacologic manipulation of gap junctions. Hum Gene Ther. 1998;9:2385-91.

219. Liu L, Li H, Guo Z, Ma X, Cao N, Zheng Y, et al. The combination of three natural compounds effectively prevented lung carcinogenesis by optimal wound healing. PLoS One. 2015;10: $\mathrm{e} 0143438$.

220. Ito A, Morita N, Miura D, Koma Y, Kataoka TR, Yamasaki H, et al. A derivative of oleamide potently inhibits the spontaneous metastasis of mouse melanoma BL6 cells. Carcinogenesis. 2004;25:2015-22.

221. Ohba Y, Kanao Y, Morita N, Fujii E, Hohrai M, Takatsuji M, et al. Oleamide derivatives suppress the spontaneous metastasis by inhibiting connexin 26. Int J Cancer. 2007;121:47-54.

222. Miura D, Kida Y, Nojima H. Camellia oil and its distillate fractions effectively inhibit the spontaneous metastasis of mouse melanoma BL6 cells. FEBS Lett. 2007;581:2541-8. 